\title{
Nonlinear response of ozone to precursor emission changes in China: a modeling study using response surface methodology
}

\author{
J. Xing ${ }^{1}$, S. X. Wang ${ }^{1}$, C. Jang ${ }^{2}$, Y. Zhu ${ }^{3}$, and J. M. Hao ${ }^{1}$ \\ ${ }^{1}$ School of Environment, and State Key Joint Laboratory of Environment Simulation and Pollution Control, Tsinghua \\ University, Beijing 100084, China \\ ${ }^{2}$ The U.S. Environmental Protection Agency, Research Triangle Park, NC 27711, USA \\ ${ }^{3}$ School of Environmental Science and Engineering, South China University of Technology, Guangzhou 510006, China
}

Received: 6 September 2010 - Published in Atmos. Chem. Phys. Discuss.: 7 December 2010

Revised: 18 May 2011 - Accepted: 25 May 2011 - Published: 31 May 2011

\begin{abstract}
Statistical response surface methodology (RSM) is successfully applied for a Community Multi-scale Air Quality model (CMAQ) analysis of ozone sensitivity studies. Prediction performance has been demonstrated through cross validation, out-of-sample validation and isopleth validation. Sample methods and key parameters, including the maximum numbers of variables involved in statistical interpolation and training samples have been tested and selected through computational experiments. Overall impacts from individual source categories which include local/regional $\mathrm{NO}_{\mathrm{x}}$ and VOC emission sources and $\mathrm{NO}_{\mathrm{x}}$ emissions from power plants for three megacities - Beijing, Shanghai and Guangzhou - were evaluated using an RSM analysis of a July 2005 modeling study. $\mathrm{NO}_{\mathrm{x}}$ control appears to be beneficial for ozone reduction in the downwind areas which usually experience high ozone levels, and $\mathrm{NO}_{\mathrm{x}}$ control is likely to be more effective than anthropogenic VOC control during periods of heavy photochemical pollution. Regional $\mathrm{NO}_{\mathrm{x}}$ source categories are strong contributors to surface ozone mixing ratios in three megacities. Local $\mathrm{NO}_{\mathrm{x}}$ emission control without regional involvement may raise the risk of increasing urban ozone levels due to the VOC-limited conditions. However, local $\mathrm{NO}_{\mathrm{x}}$ control provides considerable reduction of ozone in upper layers (up to $1 \mathrm{~km}$ where the ozone chemistry is $\mathrm{NO}_{\mathrm{x}}$-limited) and helps improve regional air quality in downwind areas. Stricter $\mathrm{NO}_{\mathrm{x}}$ emission control has a substantial effect on ozone reduction because of the shift from VOClimited to $\mathrm{NO}_{\mathrm{x}}$-limited chemistry. Therefore, $\mathrm{NO}_{\mathrm{x}}$ emission control should be significantly enhanced to reduce ozone pollution in China.
\end{abstract}

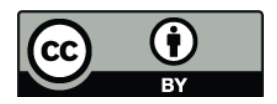

Correspondence to: S. X. Wang (shxwang@ @tsinghua.edu.cn)

\section{Introduction}

Tropospheric ozone is not only a key air pollutant that affects human health, crop productivity and natural ecosystems, but also a greenhouse gas that impacts global climate. During the past two decades, rapid economic growth in China has resulted in a significant increase in the emissions of ozone precursors such as nitrogen oxides $\left(\mathrm{NO}_{\mathrm{x}}\right)$ and volatile organic compounds (VOC) (Ohara et al., 2007; Wei et al., 2008; Zhang et al., 2009a). The emissions lead to elevated levels of ozone over urban and downwind suburban areas. In recent years, high ozone concentrations over $200 \mu \mathrm{g} \mathrm{m}^{-3}$ (approximately $103 \mathrm{ppb}$, the $1-\mathrm{h}$ maximal concentration defined by National Ambient Air Quality Standard of China, Class II) have been frequently observed by in-situ monitoring in east China (H. Wang et al., 2006; T. Wang et al., 2006; Z. Wang et al., 2006; Zhang et al., 2008; Tang et al., 2009; Ran et al., 2009; Shao et al., 2009).

Effective attainment of ground-level ozone standards depends upon the reliable estimation of ozone responsiveness to controls of its precursor emissions (Cohan et al., 2007). In general, ozone formation is classified into two categories of chemical regimes, $\mathrm{NO}_{\mathrm{x}}$-limited and VOC-limited. In the $\mathrm{NO}_{\mathrm{x}}$-limited regime, increased $\mathrm{NO}_{\mathrm{x}}$ leads to increased ozone with only slight sensitivity to VOC; in the VOC-limited (or $\mathrm{NO}_{\mathrm{x}}$-rich) regime, increased VOCs lead to increased ozone with little or even negative sensitivity to $\mathrm{NO}_{\mathrm{x}}$. Transitional conditions of dual sensitivity also occur. Classification of an area as $\mathrm{NO}_{\mathrm{x}}$-limited or VOC-limited helps determine whether $\mathrm{NO}_{\mathrm{x}}$ or VOC emissions should be targeted more aggressively in strategies to address ground-level ozone concentrations. However, ozone responsiveness is challenging to simulate due to the spatial/temporal variations of precursor emissions and meteorological conditions (Seinfeld and Pandis, 2006).

Published by Copernicus Publications on behalf of the European Geosciences Union. 
Indicators such as $\mathrm{NO}_{\mathrm{y}}, \mathrm{H}_{2} \mathrm{O}_{2} / \mathrm{HNO}_{3}$ and $\mathrm{H}_{2} \mathrm{O}_{2} /\left(\mathrm{O}_{3}+\right.$ $\mathrm{NO}_{2}$ ) simulated by air quality models are used to define the ozone chemistry in a number of studies (Sillman et al., 1995; Tonnesen et al., 2000; Zhang et al., 2009b). Air quality models (AQMs) can be a powerful regulatory tool for comparing the efficacy of various emissions control strategies and policy decisions. Advanced tools embedded in AQMs including ozone source apportionment technology (OSAT) (ENVIRON, 2002; Dunker, et al. 2002; Xu et al., 2008; X.S. Wang et al., 2009), process analysis (PA) (Jang et al., 1995; Zhang et al., 2005; Liu et al., 2010), direct decoupled methods (DDM) and a high-order decoupled direct method (HDDM) (Hakami et al., 2003; Cohan et al., 2005) enable a better understanding of ozone formation mechanisms. However, due to the computational costs and the complication of the required emission inputs and processing, using complex air quality models and still meeting time constraints of policy analysis present a difficult challenge. A promising tool for addressing this challenge, Response Surface Methodology (RSM), has been developed by using advanced statistical techniques to characterize the relationship between model outputs and input parameters in a highly economical manner. RSM is a meta-model of air quality modeling; it is a reducedform prediction model using statistical correlation structures to approximate model functions through the design of complex multi-dimension experiments. The RSM technique has recently been successfully tested and evaluated for a series of $\mathrm{PM}_{2.5}$ and ozone assessments and policy analyses in the United States (US EPA, 2006a, b).

In this paper, we develop a response surface model (RSM) using Community Multi-scale Air Quality (CMAQ), developed by the US EPA (Byun and Schere, 2006). The RSM is used to investigate ozone sensitivities to $\mathrm{NO}_{\mathrm{x}}$ and VOC emission changes in east China during a summer month. The performance of the RSM is validated by additional CMAQ simulations, referred to as out-of-sample validation, and leave-one-out cross validation. Ozone chemistry (spatially and temporally) is predicted when the precursor emissions change from $0 \%$ to $200 \%$. Different control scenarios were applied to different sectors in three megacities Beijing, Shanghai and Guangzhou - to assess the impact on ozone concentrations. Synchronous strategies to attain the ozone national standards are also discussed.

\section{Methodology}

The processes involved in developing the ozone RSM application using CMAQ include the selection of modeling domain and configuration, development of multi-dimension experimental design for control strategies, and implementation and validation of the RSM technique as shown in Fig. 1.

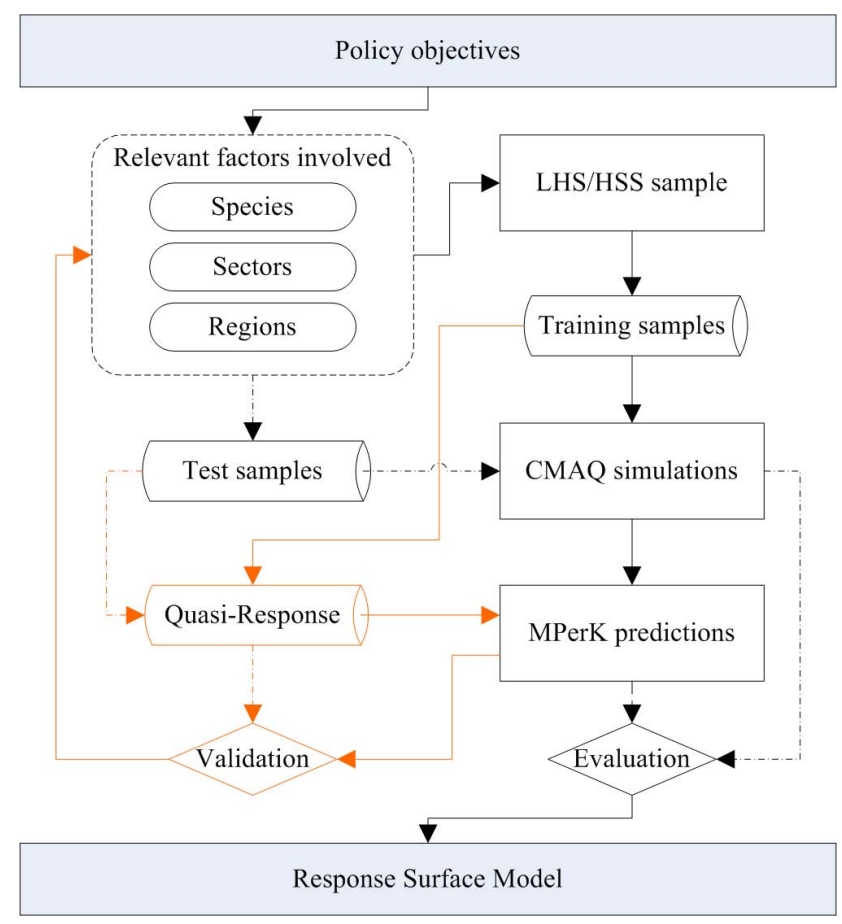

Fig. 1. Key steps in the development of response surface model (Orange lines indicate the preliminary experiment to determine the crucial parameters used to establish RSM; LHS - Latin Hypercube Sample; HSS - Hammersley quasi-random Sequence Sample; MPerK - MATLAB Parametric Empirical Kriging program).

\subsection{Emission inventory}

Emissions of $\mathrm{SO}_{2}, \mathrm{NO}_{\mathrm{x}}, \mathrm{PM}_{10}, \mathrm{PM}_{2.5}, \mathrm{BC}, \mathrm{OC}, \mathrm{NH}_{3}$, and NMVOC were calculated based on the framework of the GAINS-Asia model (Amann et al., 2008). The general method used to develop the China regional emission inventory is described in a previous paper (Klimont et al., 2009). To improve emission estimates, data for emission factors were collected from field measurements performed by Tsinghua University and from other published sources in China. A unit-based methodology was applied to estimate emissions from large point sources including coal-fired power plants, iron and steel plants, and cement plants (Zhao et al., 2008; Lei et al., 2008). Detailed local emission information aggregated from the bottom-up investigation of individual power plants, heating boilers, and industries in Beijing (BJ), Yangtze River Delta (YRD) and Pearl River Delta (PRD) are also incorporated into the national emission inventory (Li et al., 2008; Zheng et al., 2009; S.-X. Wang et al., 2010). The national emissions in 2005 are summarized in Table 1. The anthropogenic emissions of $\mathrm{SO}_{2}, \mathrm{NO}_{\mathrm{x}}, \mathrm{PM}_{10}$, $\mathrm{PM}_{2.5}, \mathrm{BC}, \mathrm{OC}, \mathrm{NH}_{3}$ and NMVOC in China were $28651 \mathrm{kt}$, $18499 \mathrm{kt}, 19237 \mathrm{kt}, 14245 \mathrm{kt}, 1595 \mathrm{kt}, 3494 \mathrm{kt}, 16556 \mathrm{kt}$, and $19406 \mathrm{kt}$, respectively. Compared to other estimates in the body of literature, e.g. Streets et al. (2003), Zhang et 
Table 1. Summary of National Emissions in China in 2005 (units, $\mathrm{kt} \mathrm{yr}^{-1}$ ).

\begin{tabular}{|c|c|c|c|c|c|c|c|c|c|}
\hline & $\mathrm{SO}_{2}$ & $\mathrm{NO}_{\mathrm{x}}$ & $\mathrm{PM}_{10}$ & $\mathrm{PM}_{2.5}$ & $\mathrm{BC}$ & $\mathrm{OC}$ & $\mathrm{NH}_{3}$ & $\mathrm{VOC}$ & \\
\hline Power plants & 15826 & 6965 & 1851 & 1024 & 49 & 20 & 1 & 295 & \\
\hline Industrial combustion & 7060 & 3272 & 2787 & 1828 & 314 & 146 & 5 & - & - \\
\hline $\begin{array}{l}\text { Industrial processes } \\
\text { Cement production } \\
\text { Iron and Steel Production }\end{array}$ & 2864 & 1824 & 6829 & 4368 & 297 & $\begin{array}{l}31 \\
23\end{array}$ & $\begin{array}{l}- \\
-\end{array}$ & 5779 & $\begin{array}{l}- \\
-\end{array}$ \\
\hline $\begin{array}{l}\text { Domestic sources } \\
\text { Bio-fuel }\end{array}$ & 2458 & 1335 & 5220 & 4656 & 749 & 2486 & 94 & 1586 & - \\
\hline Transportation & 387 & 4763 & 441 & 326 & 140 & 138 & 2 & 5601 & \\
\hline $\begin{array}{l}\text { Others } \\
\text { Open biomass burning } \\
\text { Livestock farming } \\
\text { Mineral fertilizer application }\end{array}$ & $\begin{array}{r}56 \\
- \\
-\end{array}$ & $\begin{array}{r}340 \\
- \\
-\end{array}$ & $\begin{array}{r}2110 \\
- \\
-\end{array}$ & $\begin{array}{r}2044 \\
- \\
-\end{array}$ & $\begin{array}{r}46 \\
- \\
-\end{array}$ & $\begin{array}{r}453 \\
- \\
-\end{array}$ & $\begin{array}{r}14 \\
7161 \\
8354\end{array}$ & 6054 & $\begin{array}{r}5871 \\
- \\
-\end{array}$ \\
\hline National total emissions & 28651 & 18499 & 19237 & 14245 & 1595 & 3494 & 16556 & 19406 & \\
\hline
\end{tabular}

al. (2009a), the uncertainties in anthropogenic emissions in our base year emissions are relatively low. The uncertainties (i.e., $95 \%$ confidence intervals around the central estimates) of the $\mathrm{NO}_{\mathrm{x}}$ and VOC emission inventory used in this study are $-10 \%$ to $36 \%$ (Zhao et al., 2011) and $-44 \%$ to $109 \%$ (Wei et al., 2008).

\subsection{MM5/CMAQ modeling domain and configuration}

The air quality model used to develop the response surface model is the CMAQ modeling system (ver. 4.7). A one-way nested technique was employed in this study. Modeling domain 1 covers almost all of China with a $36 \times 36 \mathrm{~km}$ horizontal grid resolution and generates the boundary conditions for a nested domain with a $12 \times 12 \mathrm{~km}$ resolution over highlypopulated Eastern China (domain 2), as shown in Fig. 2a. The RSM runs were based on the $12 \times 12 \mathrm{~km}$ domain. Three megacities, Beijing, Shanghai and Guangzhou, within domain 2 were selected as target areas for analysis. The vertical resolution of CMAQ includes fourteen layers from the surface to the tropopause with denser layers at lower altitudes to resolve the planetary boundary layer (PBL). The Carbon Bond Mechanism (CB05) with aqueous and aerosol extensions and the AREO5 aerosol mechanism were chosen for the gas-phase chemistry and aerosol module, respectively. A spin-up period of six days was used for model simulations to reduce the influence of initial conditions on model results. The CMAQ simulation period is the entire month of July 2005. A complete description of CMAQ, meteorological, emissions, and initial and boundary condition inputs used for this analysis are discussed in Xing et al. (2010) and L.-T. Wang et al. (2010). The CMAQ simulations of this modeling system have been validated through comparison with observations of satellite retrievals and surface monitoring data. We compared the simulated ozone concentration with the observed data of six monitoring stations in Beijing, including five urban sites in Qianmen, Dongsi,
Tiantan, Aoti, Nongzhanguan, Gucheng, and one rural site as Dingling, which were described in Streets et al. (2007) and Wang et al. (2008). The NMB (normalized mean bias) of simulated hourly ozone concentration between 08:00 a.m.08:0 p.m. (Beijing time) was $9 \%$, with a 0.76 correlation coefficient. Additionally, the performances of the CMAQ simulation on ozone concentrations using the same bottom-up emission inventories were validated by $\mathrm{Li}$ et al. (2008) for the Yangtze River Delta, and S.-X. Wang et al. (2010) for Beijing. $\mathrm{NO}_{2}$ as one important precursor of ozone has been evaluated as well (Xing et al., 2010). The simulated $\mathrm{NO}_{2}$ vertical column density over China showed good agreement with those retrieved from OMI, and the normal mean bias (NMBs) range from $-17 \%$ to $12 \%$, which are comparable with the errors from satellite retrievals. CMAQ simulated $\mathrm{NO}_{2}$ concentrations are also comparable with the observation data in Beijing, Shanghai, and Guangzhou, and the NMBs range from $-25 \%$ to $15 \%$. We've also compared the simulated VOC mixing ratios with the monitoring data in Beijing and Guangzhou. The simulated surface VOC mixing ratio in Beijing is $372 \mathrm{ppbC}$ in summer, which is comparable with the observed value, i.e. $378 \mathrm{ppbC}$ reported by Duan et al. (2008). The simulated VOC mixing ratio in Guangzhou is $380 \mathrm{ppbC}$ in summer, which is $17 \%$ lower than the observed data, i.e., $460 \mathrm{ppbC}$ reported by Shao et al. (2009).

\subsection{RSM experiment design}

RSM uses statistical techniques to build response relationships between a response variable (ozone concentration in this study) and a set of control factors of interest, e.g. emissions of precursor pollutants from particular sources and locations, through designed experiments (Box and Draper, 2007). RSM is a meta-model built upon multi-“brute force" model simulations, which can help avoid the uncertainties from systemic complexity. There are two major advantages of the RSM approach. First, conducting the sensitivity 


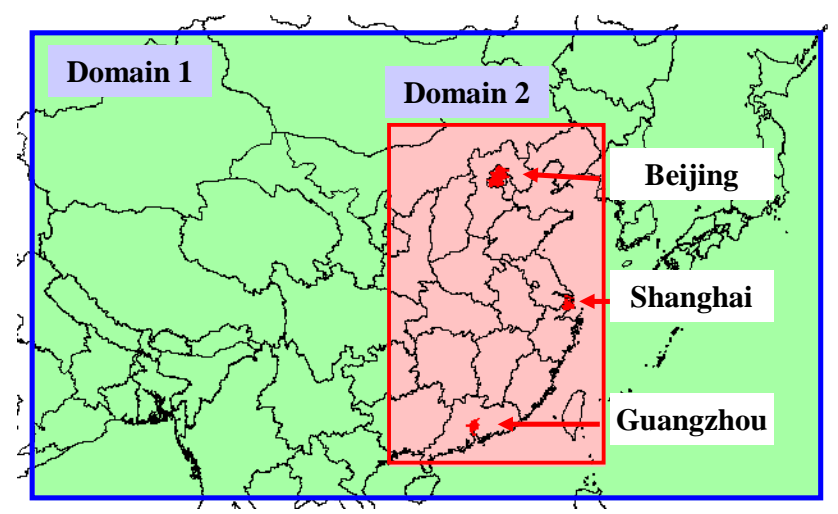

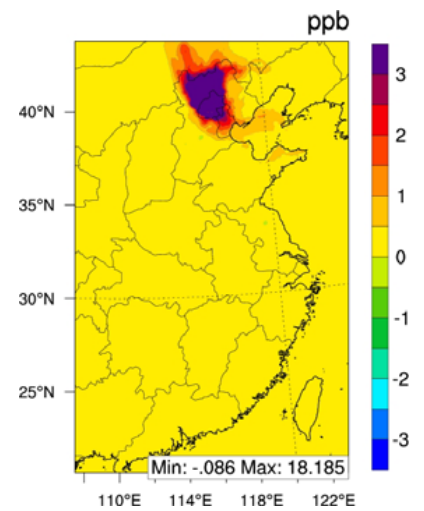

Beijing

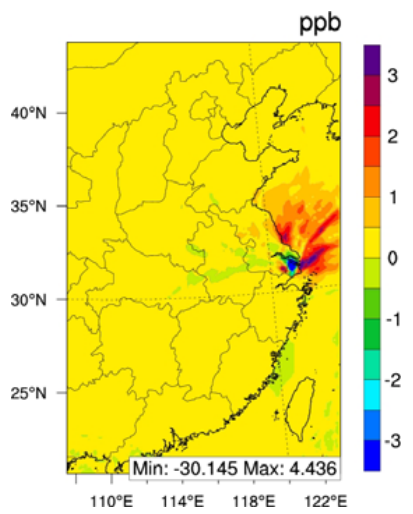

Shanghai

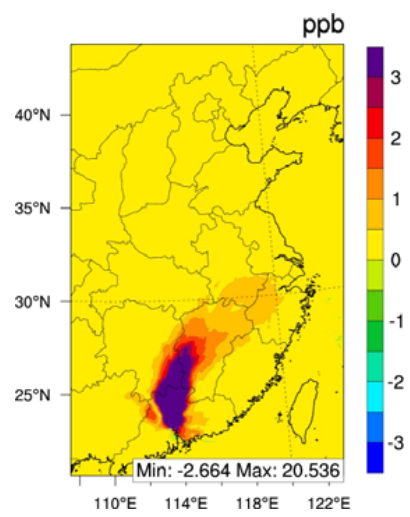

Guangzhou

Fig. 2. Map of the CMAQ/RSM modeling domain and interactions among three cities. (a) CMAQ and RSM modeling domain; (b) change in ozone concentration (Baseline scenario minus the control scenario which zeroed out all emissions in three cities, monthly mean of 1-h daily ozone maxima in July 2005, unit:ppb).

analysis requires a number of control scenario runs which is inefficient using a "brute force" method. RSM uses advanced statistical techniques to characterize the multi-simulation results, which makes the method highly efficient. The sensitivity analysis can be easily and quickly done using RSM and no extra CMAQ simulations are needed. Second, we often need to know how much emissions shall be reduced to attain the ambient air quality standard. RSM allows us to calculate the emission reduction ratio attaining a certain concentration target. "Brute force" method does not have the ability to o that.

Due to the limitation of computational capability, experiment design is the key issue to building reliable responses with limited samples (Santner et al., 2003), and it is requisite to ensure the accuracy of the prediction model. Previous studies of $\mathrm{O}_{3}$ control analyses explored the overall impacts of two factors (total $\mathrm{NO}_{\mathrm{x}}$ and total VOC emission) on ozone that may be successfully derived from statistical interpolation of dozens of training samples (Milford et al., 1989; Shih et al., 1998; Fu et al., 2006). The interpolation is much more complicated when the precursor emissions are separated by pollutants, sectors and regions (Wang and Milford, 2001). Constraints are placed on the experimental design space, i.e. the region over which the response is studied, to a set of variables that parameterize a set of possible emissions control strategies and evaluate the change in ambient ozone levels that result from a change in emissions.

The species of pollutants, as well as its source category relevant to the policy analysis of interest, are chosen as our control targets. The experimental design carefully considered factors that would provide maximum information for use in comparing relative efficacy of different emissions control strategies. To develop independent response surfaces for particular urban areas, as well as a generalized response surface for all other locations (outside of the particular urban areas), we applied a regional design for the RSM experiment. In this study, the particular cities selected were Beijing, Shanghai and Guangzhou. Local versus regional impacts have been teased out for the three cities. The local emissions in those three cities were grouped together as one region (Region A), and the rest of the country within RSM 
Table 2. Sample methods and key parameters used for ozone response surface establishment.

\begin{tabular}{llll}
\hline RSM case & Variable & Sample method & Number of samples \\
\hline LHS1-30 & $\begin{array}{l}\text { Total } \mathrm{NO}_{\mathrm{x}} \text { emissions } \\
\text { Total VOC emissions }\end{array}$ & $\begin{array}{l}\text { Latin Hypercube Sampling } \\
\text { without margin process }\end{array}$ & 30 \\
\hline HSS6-200 & $\mathrm{NO}_{\mathrm{x}}$ from power plants in Region A*; & $\begin{array}{l}\text { Hammersley quasi-random } \\
\text { Sequence Sample with margin }\end{array}$ & 200 \\
& $\mathrm{NO}_{\mathrm{x}}$ from Area sources in Region A; & $\begin{array}{l}\text { Sem } \\
\text { level as 6 }\end{array}$ & \\
& $\mathrm{NO}_{\mathrm{x}}$ from power plants in Region B; & & \\
& $\mathrm{NO}_{\mathrm{x}}$ from Area sources in Region B; & \\
& VOC emissions in Region B; & \\
\hline
\end{tabular}

* Region A: three cities of Beijing, Shanghai and Guangzhou; Region B: other areas in domain 2.

domain (i.e., domain 2, see Fig. 2a) was grouped as another region (Region B). In our analysis, Region A represents local emission in each city. To test the independence of the three cities, sensitivity analyses were conducted to calculate the impact of one city's emissions on the other two, which is given by the differences between the baseline simulation and the control simulation which zeroed out all emissions in the selected cities, as shown in Fig. 2b. The impact of emissions from each of the cities on the other cities was negligible - less than $0.5 \mathrm{ppb}$. Therefore, we determined that the selection of these areas allows the RSM to analyze air quality changes in these urban areas independent of one another. On a local or regional basis, the ozone precursor emissions are categorized into $\mathrm{NO}_{\mathrm{x}}$ emissions from power plants (PP, represents point sources in higher layers), $\mathrm{NO}_{\mathrm{x}}$ emissions from other area sources $(\mathrm{OTH}$, represents area and mobile sources at the surface layer), and VOC emissions, as shown in Table 2. We defined "Emission Ratio" as the ratio of the changed emissions relative to the baseline emissions (e.g., a $40 \%$ reduction would be an Emission Ratio of 0.6.).

Table 2 provides the sampling method and number of training samples used during model development. A method is adopted in this study such as the Latin Hypercube Sample (LHS) (Iman et al., 1980), a widely-used filling method which ensures that the ensemble of random samples is representative of actual variability. Further, in order to ensure the reproducibility of this study, we also chosen the Hammersley quasi-random Sequence Sample (HSS) method (Hammersley, 1960) which can quickly "fill up" the space in a well-distributed pattern with low discrepancy. Based on the uniformly-distributed LHS/HSS with a relatively equiprobable interval over the range, additional margin processing was conducted to improve the performance of the model's predictions at the margins. Here we chose a power function to apply to the samples from uniformly-distributed LHS/HSS:

$$
\begin{aligned}
& T X n= \\
& \begin{cases}X, & n=1 \\
\left(\frac{X-a}{b-a} \times 2\right)^{n} \times(b-a)+a, & X \leq a+\frac{b-a}{2}, n>1 \\
{\left[1-\left(\frac{b-X}{b-a} \times 2\right)^{n}\right] \times(b-a)+a,} & X>a+\frac{b-a}{2}, n>1\end{cases}
\end{aligned}
$$

where $X$ is sampled from uniformed LHS/HSS in section [ $a$, $b]$ (in this study we choose $[0,2]$, which means the emission changes are from $100 \%$ decrease and $100 \%$ increase of emissions); $T X n$ is the sample result after margin processing; $n$ is the order indicting the marginal level.

Another purpose of margin processing is to sample more possible situations. Normally we assume the variables have no direct interaction with each other. However, the variables considered in such a predictive system are related, e.g., total $\mathrm{VOC}=\mathrm{VOC}$ from local sources (variable $a$ ) $+\mathrm{VOC}$ from regional sources (variable $b$ ). Samples generated by uniform methods would provide even distributions for individual source categories, but uneven distributions for total emissions (here as total VOC) with fewer samples located in the marginal areas and its density of distribution, as the $N$ (representing the number of pollution sources) power function, as shown in Fig. 3b. Therefore, the margin process is used to enlarge the sample density located in the marginal areas. The optimized marginal level $n$ is selected through computational tests during preliminary experiments (see details in Sect. 3.1.2).

In LHS1-30, we used 30 training samples generated by the LHS method to map the ozone mixing ratios vs. total$\mathrm{NO}_{\mathrm{x}}$ and total-VOC Emission Ratios. In the case of HSS6200, 4 types of $\mathrm{NO}_{\mathrm{x}}$ emission sources and 2 types of VOC emission sources were involved, the number of training samples and optimized margin levels are determined according to the results of preliminary experiments, shown as orange lines in Fig. 1. Due to the computational cost of hundreds of CMAQ simulations, we adopted the "quasi-response" of ozone to precursor emissions based on statistical calculations done during preliminary experiments. 


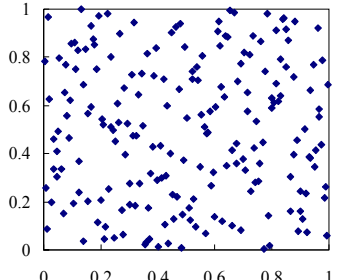

LHS1

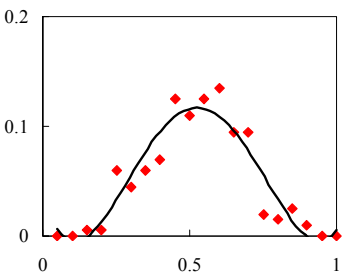

LHS1

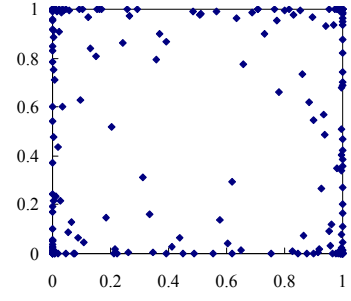

LHS6

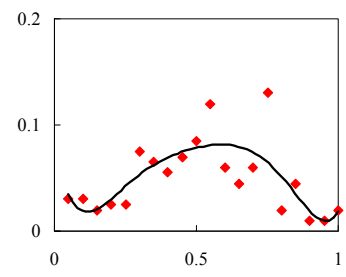

LHS6

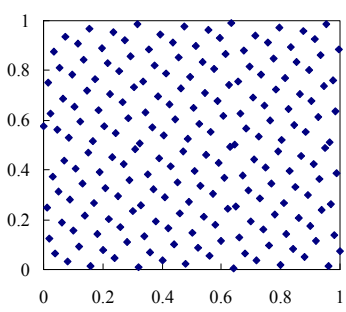

HSS 1

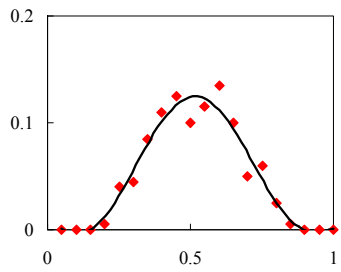

HSS1
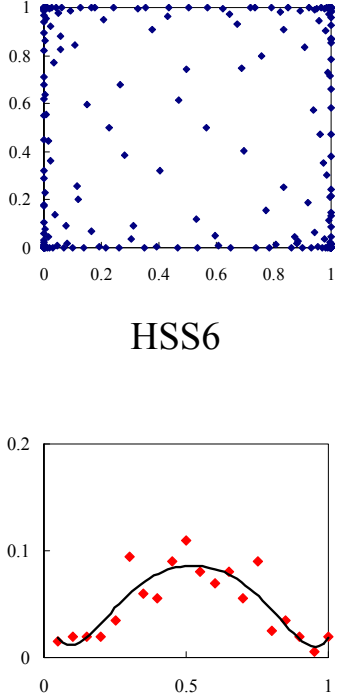

HSS6

Fig. 3. Margin processing conducted in sampling. (a) Joint distribution of two individual variables (200 samples in [0 1]). (b) Distribution density of weighted mean of 4 random variables which equals 4 individual variables respectively multiply the "weight coefficients" $(A(i))$ which were set to be $A(i)=\frac{2 i}{(n+1) n}$, red-point represents sample distribution density, dark-line is the fitting trend-line with 4th power.

The "quasi-response" is based on the results of LHS1-30 which describes the relationship between the ozone concentrations with the Emission Ratios of total $\mathrm{NO}_{\mathrm{x}}$ and VOC. In order to set up the ozone "quasi-response" to the Emission Ratios of each $\mathrm{NO}_{\mathrm{x}} / \mathrm{VOC}$ emission source category, it is necessary to set up a quasi-mapping relation between the Emission Ratios of each emission source category and total emissions. Since total emissions are the sum of individual emission source category, the Emission Ratio of total emissions is the weighted mean of the Emission Ratios of each emission source category:

$$
\begin{aligned}
t \mathrm{NOX} & =\sum_{i=1}^{m} \mathrm{NOX}_{i}, R-t \mathrm{NOX} \\
& =\left[R-\mathrm{NOX}_{1}, \cdots, R-\mathrm{NOX}_{m}\right] \cdot A^{m \times 1}
\end{aligned}
$$

$$
\begin{aligned}
t \mathrm{VOC} & =\sum_{j=1}^{n} \mathrm{VOC}_{j}, R-t \mathrm{VOC} \\
& =\left[R-\mathrm{VOC}_{1}, \cdots, R-\mathrm{VOC}_{n}\right] \cdot B^{n \times 1}
\end{aligned}
$$

where $t \mathrm{NOX}$ and $t \mathrm{VOC}$ are respectively total $\mathrm{NO}_{\mathrm{x}}$ emissions and total VOC emissions; $\mathrm{NOX}_{i}$ and $\mathrm{VOC}_{j}$ are respectively $\mathrm{NO}_{\mathrm{x}}$ and VOC emissions from source category $i$ and $j ; R$ $t$ NOX and $R-t \mathrm{VOC}$ are respectively the Emission Ratio of total $\mathrm{NO}_{\mathrm{x}}$ emissions and total-VOC emissions; $R-\mathrm{NOX}_{i}$ is the Emission Ratio of $\mathrm{NO}_{\mathrm{x}}$ emissions from source category $i ; R-\mathrm{VOC}_{j}$ is the Emission Ratio of VOC emissions from source category $j ; A^{m \times 1}$ and $B^{n \times 1}$ are the weight coeffi- cients for each $\mathrm{NO}_{\mathrm{x}}$ and $\mathrm{VOC}$ source categories reflecting the category's contribution defined by

$$
\begin{aligned}
& \operatorname{NOX}_{i}=t \mathrm{NOX} \times A(i), t \mathrm{NOX}=\sum_{i=1}^{m} \mathrm{NOX}_{i}=\sum_{i=1}^{m} t \mathrm{NOX} \times A(i) \\
& \mathrm{VOC}_{j}=t \mathrm{VOC} \times B(j), t \mathrm{VOC}=\sum_{j=1}^{n} \mathrm{VOC}_{j}=\sum_{j=1}^{n} t \mathrm{VOC} \times B(j) ;
\end{aligned}
$$

in the preliminary experiments, the "weight coefficients" were set to be $A(i)=\frac{2 i}{(m+1) m}$ and $B(j)=\frac{2 j}{(n+1) n}$.

It should be noted that such an assumption is not always valid since the long-range transport of regional emissions and large point sources would create different impacts. However, such an assumption allows us to explore the sensitivity of critical parameters to prediction bias through hypothetical computational testing efficiently (see details in Sect. 3.1.2). Finally, the sample method and key parameter used to build HSS6-200 were determined (see Table 2).

\subsection{Statistical and prediction method}

Each training sample represents one emission control scenario which is simulated by CMAQ and then used for RSM. Based on those simulated ozone responses, the RSM prediction system is statistically generalized by an MPerK (MATLAB Parametric Empirical Kriging) program followed by Maximum Likelihood Estimation - Experimental Best Linear Unbiased Predictors (MLE-EBLUPs) (Santner et al., 2003). The calculation is based the following equation: 


$$
\begin{aligned}
Y\left(x_{0}\right) & =Y_{0}=\sum_{j=1}^{d} f_{j}(x) \beta_{j}+Z(x) \equiv \boldsymbol{f}_{0}^{T} \boldsymbol{\beta} \\
& +\boldsymbol{\gamma}_{0}^{T} \boldsymbol{R}^{-1}\left(\boldsymbol{Y}^{n}-\mathbf{F} \boldsymbol{\beta}\right)
\end{aligned}
$$

where $Y\left(x_{0}\right)$ is the predicted concentration from RSM; $\boldsymbol{f}_{0}$ is the $d \times 1$ vector of regression functions for $Y_{0} ; \mathbf{F}$ is the $n \times d$ matrix of regression functions for the training data; $\boldsymbol{R}$ is the $n \times n$ matrix of correlations among the $\boldsymbol{Y}^{n} ; \boldsymbol{\gamma}_{0}$ is the $n \times 1$ vector of correlations of $\boldsymbol{Y}^{n}$ with $Y_{0} ; \boldsymbol{\beta}$ is the $d \times 1$ vector of unknown regression coefficients and the generalized least squares estimator of $\boldsymbol{\beta}=\left(\mathbf{F}^{T} \boldsymbol{R}^{-1} \mathbf{F}\right)^{-1} \mathbf{F}^{T} \boldsymbol{R}^{-1} \boldsymbol{Y}^{n}$.

The Product Power Exponential correlation is chosen as the correlation function for prediction:

$R(h \mid \xi)=\prod_{i=1}^{d} \exp \left[-\theta_{i}\left|h_{i}\right|^{p_{i}}\right]$

where $\xi=(\theta, p)=\left(\theta_{1}, \ldots, \theta_{d}, p_{1}, \ldots p_{d}\right)$ with $\theta_{i} \geq 0$ and $0<$ $p_{i} \leq 2$, the $\xi$ estimator is the maximum likelihood estimate (MLE).

In order to confirm the reliability of RSM reproducing CMAQ simulations, the above prediction method is validated through "leave-one-out cross validation" (LOOCV), out-ofsample validation and 2-D isopleths validation. The definition of LOOCV is to use a single sample from the original datasets as the validation data, and the remaining sample as the training data to build the RSM prediction. Each sample in the datasets is used once as validation data. For example, for $N$ training data $(d 1, d 2 \ldots d N)$, the sample $i(d i)$ has been selected as the validation data, and the remaining samples $(d 1, d 2 \ldots d(i-1), d(i+2) \ldots d N)$ are used to build RSM to predict the sample $i$ and to make a comparison. Out-ofsample validation needs additional CMAQ cases which are not included in training samples, then RSM predictions are compared with those extra CMAQ simulations. Validation of 2-D isopleths compares the prediction results of 2-D isopleths with that of a multi-dimension RSM which is used to evaluate the stability of RSM with larger dimensions.

Point-to-point data are compared through correlation analysis and error analysis. The correlation coefficient $(R)$ and Mean Normalized Error (MNE) were calculated using the following equations:

$$
\begin{aligned}
& R=\sqrt{\frac{\left[\sum_{i=1}^{N}\left(P_{i}-\bar{P}\right)\left(S_{i}-\bar{S}\right)\right]^{2}}{\sum_{i=1}^{N}\left(P_{i}-\bar{P}\right)^{2} \sum_{i=1}^{N}\left(S_{i}-\bar{S}\right)^{2}}} \\
& \mathrm{MNE}=\frac{1}{N} \sum_{i=1}^{N} \frac{\left|P_{i}-S_{i}\right|}{S_{i}}
\end{aligned}
$$

where $P_{i}$ and $S_{i}$ are the RSM-predicted and CMAQsimulated value of the $i$ th data in the series; and $\bar{P}$ and $\bar{S}$ are the average simulated and observed value over the series.

\section{Results and discussion}

\subsection{Development and validation of the RSM-Ozone system}

The results of the RSM modeling case LHS1_30 were used as a "quasi-response" in preliminary experiments. The results of the modeling case HSS6_200 were compared with that of LHS1_30 through LOOCV, out-of-sample validation and 2$D$ isopleths validation. Sensitivity analyses were conducted to check the RSM prediction performance for the margins, sample numbers, and variable numbers.

\subsubsection{Validation of RSM performance}

Using the LOOCV method, the ozone levels simulated by CMAQ and predicted by RSM were compared for both case LHS1-30 (31 pairs of data) and case HSS6-200 (201 pairs of data), as shown in Fig. 4. A strong linear relationship $(y=x)$ between CMAQ and RSM datasets were found in all areas for both cases, with the R-square values larger than 0.99. For Beijing, Shanghai, Guangzhou and East China, the MNE of LHS1-30/HSS6-200 were respectively $0.2 \% / 0.6 \%$, $0.4 \% / 0.6 \%, 0.9 \% / 0.5 \%$, and $0.3 \% / 0.2 \%$, and the maximum normalized errors (NEs) were respectively $1.5 \% / 4.1 \%$, $2.7 \% / 8.3 \%, 6.0 \% / 5.5 \%$, and $1.6 \% / 1.8 \%$. These results suggest that the RSM prediction performs well for all levels of ozone mixing ratios in both the LHS1-30 and HSS6-200 cases.

Extra CMAQ simulations with certain NOx and VOC Emission Ratios, as seen in Table 3, were conducted to validate the RSM predictions. For Beijing, Shanghai, Guangzhou and East China, the MNEs of LHS1-30/HSS6200 were respectively $1.9 \% / 1.2 \%, 0.7 \% / 0.4 \%, 0.5 \% / 0.5 \%$ and $0.5 \% / 0.6 \%$, and the maximum NEs of LHS1-30/HSS6200 were respectively $3.9 \% / 3.5 \%, 1.8 \% / 2.0 \%, 1.8 \% / 5.5 \%$ and $1.6 \% / 1.8 \%$. These results indicate that the RSM predictions provide good accuracy compared to the CMAQ simulations, though relatively larger biases occurred for low ozone mixing ratios.

The 2-D isopleths of the ozone responses to changes of total $\mathrm{NO}_{\mathrm{x}}$ and total VOC emissions in HSS6-200 are shown in Fig. 5a. From Fig. 5a, we can see a strong non-linear response of ozone to precursor emissions in the three megacities. RSM is able to reveal such non-linear relationships efficiently and reliably. The 2-D isopleths of NE, as shown in Fig. 5b, represent the differences between LHS1-30 and HSS6-200. The errors are below $1 \%$. When $\mathrm{NO}_{\mathrm{x}}$ emissions ratios are below $0.4\left(\mathrm{NO}_{\mathrm{x}}\right.$ emissions reduced $\left.60 \%\right)$, larger NEs $(2-15 \%)$ are found because of the margin effects. The $\mathrm{NO}_{\mathrm{x}} / \mathrm{VOC}$ Emission Ratios corresponding to the inflection points are consistent in both LHS1-30 and HSS6200 , confirming the stability of RSM with large dimensions (HSS6-200). 
Table 3. Normalized errors of RSM predicted daily 1-hour maximum ozone mixing ratio compared to simulated result by CMAQ through out-of-sample validation, $\%$.

\begin{tabular}{|c|c|c|c|c|c|c|c|c|c|c|}
\hline \multirow[b]{2}{*}{ No } & \multicolumn{2}{|c|}{ Emission Ratio } & \multicolumn{2}{|c|}{ Beijing } & \multicolumn{2}{|c|}{ Shanghai } & \multicolumn{2}{|c|}{ Guangzhou } & \multicolumn{2}{|c|}{ East China } \\
\hline & $\mathrm{NO}_{\mathrm{x}}$ & VOC & LHS1-30 & HSS6-200 & LHS1-30 & HSS6-200 & LHS1-30 & HSS6-200 & LHS1-30 & HSS6-200 \\
\hline 1 & 0.1 & 1 & 2.0 & -2.5 & 1.8 & -3.6 & -1.5 & -0.7 & -0.9 & -0.2 \\
\hline 2 & 0.3 & 1 & 3.2 & -1.4 & 0.5 & -2.0 & -0.3 & -0.2 & -1.6 & 0.1 \\
\hline 3 & 0.5 & 1 & 2.8 & 1.3 & -1.0 & 0.0 & 0.1 & -0.1 & -1.5 & 0.0 \\
\hline 4 & 0.7 & 1 & 2.3 & 1.6 & -0.9 & 1.1 & -0.2 & 0.5 & -1.6 & -0.8 \\
\hline 5 & 1.5 & 1 & -1.3 & -0.4 & 0.5 & -0.5 & 0.3 & 0.4 & -0.3 & -0.2 \\
\hline 6 & 1.9 & 1 & -3.9 & -0.2 & -1.0 & -0.6 & -0.1 & -0.3 & -0.2 & 0.0 \\
\hline 7 & 1 & 0.1 & 0.3 & -2.0 & 0.9 & -1.0 & -0.6 & 0.3 & -0.1 & -1.2 \\
\hline 8 & 1 & 0.3 & 0.7 & -1.4 & 0.8 & -0.8 & 0.0 & 0.5 & 0.0 & -1.4 \\
\hline 9 & 1 & 0.5 & 0.9 & -0.9 & 0.5 & -0.9 & 0.4 & 0.5 & -0.3 & -1.5 \\
\hline 10 & 1 & 0.7 & 1.0 & -0.6 & 0.1 & -1.1 & 0.3 & 0.0 & -0.3 & -1.6 \\
\hline 11 & 1 & 1.5 & 1.5 & 0.0 & -0.7 & -0.7 & 0.0 & 0.2 & 0.0 & -1.4 \\
\hline 12 & 1 & 1.9 & 1.7 & 0.3 & -1.3 & -0.5 & -0.1 & 0.7 & -0.1 & -1.1 \\
\hline 13 & 0.1 & 0.1 & 1.1 & -3.5 & 0.5 & -1.7 & -2.0 & -1.8 & -0.7 & -0.6 \\
\hline 14 & 0.3 & 0.3 & 3.5 & -1.9 & 1.2 & -1.6 & -0.5 & -1.8 & -0.1 & -0.1 \\
\hline 15 & 0.5 & 0.5 & 2.6 & 1.0 & -0.4 & 0.6 & -0.3 & -1.0 & 0.1 & -0.1 \\
\hline 16 & 0.7 & 0.7 & 2.2 & 1.4 & -0.1 & 1.2 & -0.2 & 0.1 & -0.1 & -0.8 \\
\hline 17 & 1.5 & 1.5 & -0.5 & -0.3 & 0.4 & 0.0 & 0.1 & 0.3 & 0.2 & -0.2 \\
\hline 18 & 1.9 & 1.9 & -2.1 & -0.3 & -0.8 & -0.3 & -0.6 & 0.2 & -1.0 & 0.0 \\
\hline $\mathrm{Me}$ & Norm & & 1.9 & 1.2 & 0.7 & 0.4 & 0.5 & 0.5 & 0.5 & 0.6 \\
\hline Max & nal No & Error & 3.9 & 3.5 & 1.8 & 2.0 & 1.8 & 5.5 & 1.6 & 1.8 \\
\hline
\end{tabular}
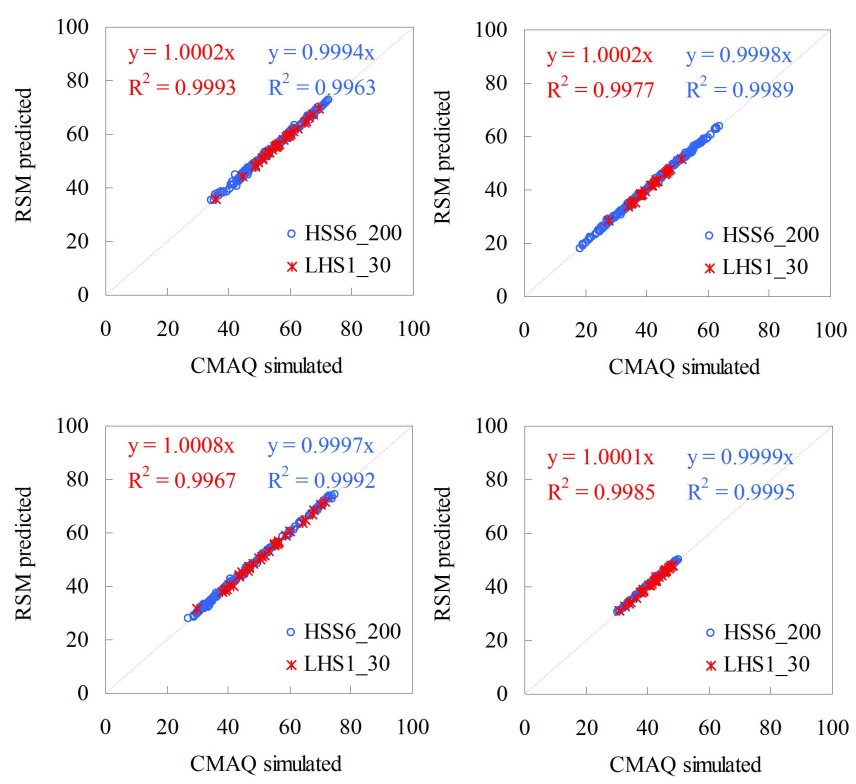

Fig. 4. Leave-one-out cross-validation of two RSM-Ozone cases (monthly mean of daily 1-h maxima Ozone, ppb).

\subsubsection{Sensitivity of RSM predictions to key parameters}

As we discussed in Sect. 2.2, the optimized marginal level (n) was determined through computational experiments with the "quasi-response" built in Sect. 2.3. Test samples are defined as all $\mathrm{NO}_{\mathrm{x}}$ and VOC emission levels from 0.0 to 2.0 where 1.0 is the base case. Emission levels were stepped by 0.1 , providing a total of 441 test pairs. Sensitivities of prediction performance to the margin level are shown in Fig. 6. Six variables including $4 \mathrm{NO}_{\mathrm{x}}$ source categories and 2 VOC source categories are involved, sampled by two methods - LHS and HSS. In quasi-HSS-4vs2 $\left(4 \mathrm{NO}_{\mathrm{x}}\right.$ source categories and 2 VOC source categories, 100-160 samples), obvious prediction performance improvement is found after margin processing. Similar improvement is found in quasiLHS-4vs2 $\left(4 \mathrm{NO}_{\mathrm{x}}\right.$ source categories and 2 VOC source categories, 160 samples), with level 3-4 marginal processing. The MNEs are reduced more than $50 \%$, from $8 \%$ to $3 \%$.

In order to explore the sensitivity of the prediction performance to number of samples and variables, we conducted a series of computational experiments with different variable and sample numbers using both LHS and HSS with margin processing, as seen in Fig. 7. For good prediction performance with an $\mathrm{MNE}<1 \%$ and an $R>0.99$, when there are few variables such as $2(1 \mathrm{vs} 1)$ and $4(2 \mathrm{vs} 2)$, only a few training samples ( $<30$ for $2(1 \mathrm{vs} 1)$ and $<60$ for $4(2 \mathrm{vs} 2)$ ) are needed. Errors increase with an increase in variables. For 


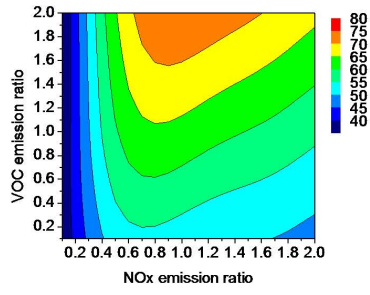

Beijing

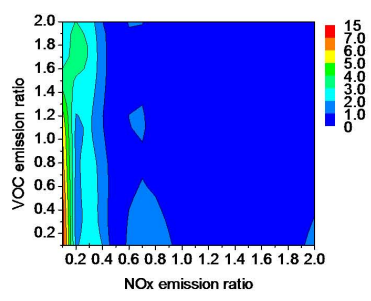

Beijing

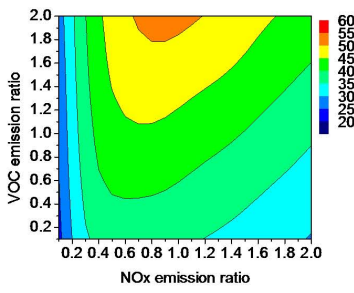

Shanghai

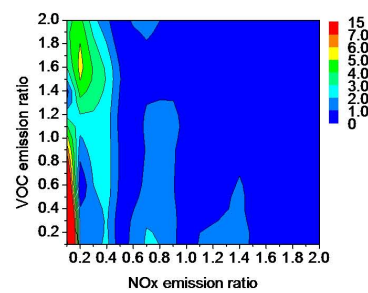

Shanghai

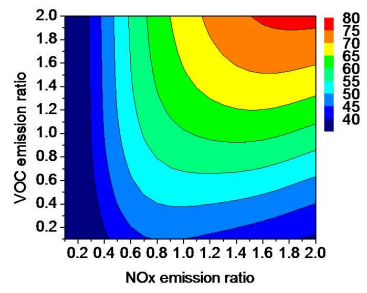

Guangzhou

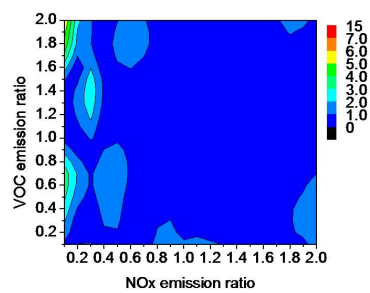

Guangzhou

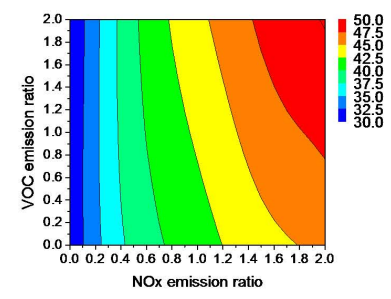

East China

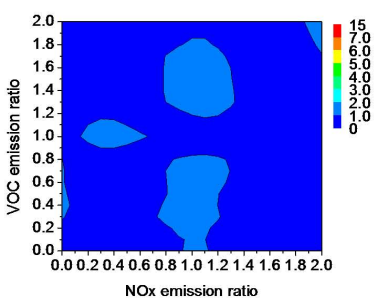

East China

Fig. 5. 2-D isopleths validation of HSS6-200, (a) 2-D Isopleths of Ozone from HSS6-200 (monthly mean of daily 1-h maxima, July 2005, ppb). (b) Normalized error (equal absolute (HSS6-200 minus LHS1-30) divided by LHS1-30, \%).
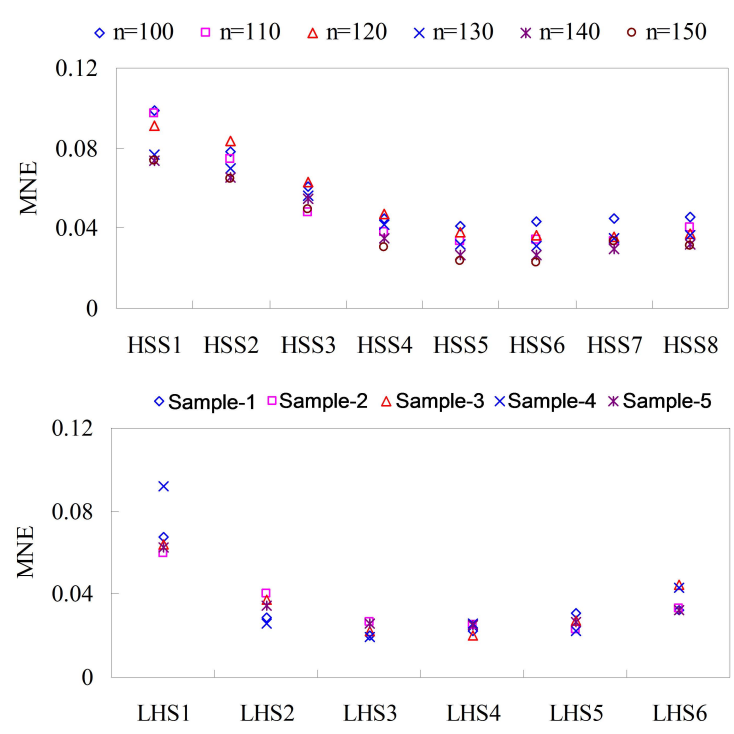

Fig. 6. Sensitivity of prediction performances to marginal level through computational experiments. (a) Quasi-HSS-4vs2 (4 types of $\mathrm{NO}_{\mathrm{x}}$ with 2 types of VOC sources, 100-160 samples); (b) quasiLHS-4vs2 (4 types of $\mathrm{NO}_{\mathrm{x}}$ with 2 types of VOC sources, 160 samples).

6(4vs2) variables and over 150 samples, the MNEs are still within an acceptable range $(<2 \%)$ and the correlation coefficient $(R)$ is over 0.99 . However, with $8(6 \mathrm{vs} 2)$ and $10(8 \mathrm{vs} 2)$ variables, MNEs increase to $5 \%$ and $7 \%$ and the correlation coefficients decrease to 0.8 and 0.5 , respectively. Increasing sample numbers does not reduce the errors caused by the increase of variables, since the sample space is sharply enlarged with the increase of dimensions. That indicates there is a risk of statistical failure. The number of variables is the most crucial parameter that should be determined through computational experiments before an RSM case is established.

\subsection{Application of ozone RSM in Beijing, Shanghai and Guangzhou}

\subsubsection{Identification of ozone chemistry}

In the isopleths of ozone response to changes of precursor emissions predicted by RSM, the $\mathrm{NO}_{\mathrm{x}}$ Emission Ratio at the peak ozone concentrations under baseline VOC emissions is defined as the peak ratio, or ridge-line ratio. When the peak ratio is lower than the current $\mathrm{NO}_{\mathrm{x}}$ Emission Ratio (baseline Emission Ratio $=1$ ), reducing $\mathrm{NO}_{\mathrm{x}}$ emissions may not effectively reduce ozone levels. When the peak ratio is higher than the current $\mathrm{NO}_{\mathrm{x}}$ Emission Ratio, the control of $\mathrm{NO}_{\mathrm{x}}$ emissions will effectively reduce ozone levels. The use of the peak ratio as an index not only helps identify the ozone response regime, but also indicates how much $\mathrm{NO}_{\mathrm{x}}$ emission reduction may be needed to avoid potential negative impacts on ozone concentrations. We also compared the spatial distribution of $\mathrm{NO}_{\mathrm{y}}$ mixing ratio with the peak ratio.

Due to the spatial variations of precursor concentrations, the ozone response varies in different locations ( $\mathrm{Xu}$ et al., 2008). The spatial distributions of ozone concentrations, $\mathrm{NO}_{\mathrm{y}}$ concentrations and peak ratios over three selected urban areas are shown in Fig. 8. The areas with peak ratio values less than 1 are mainly located in the city center of Beijing, 

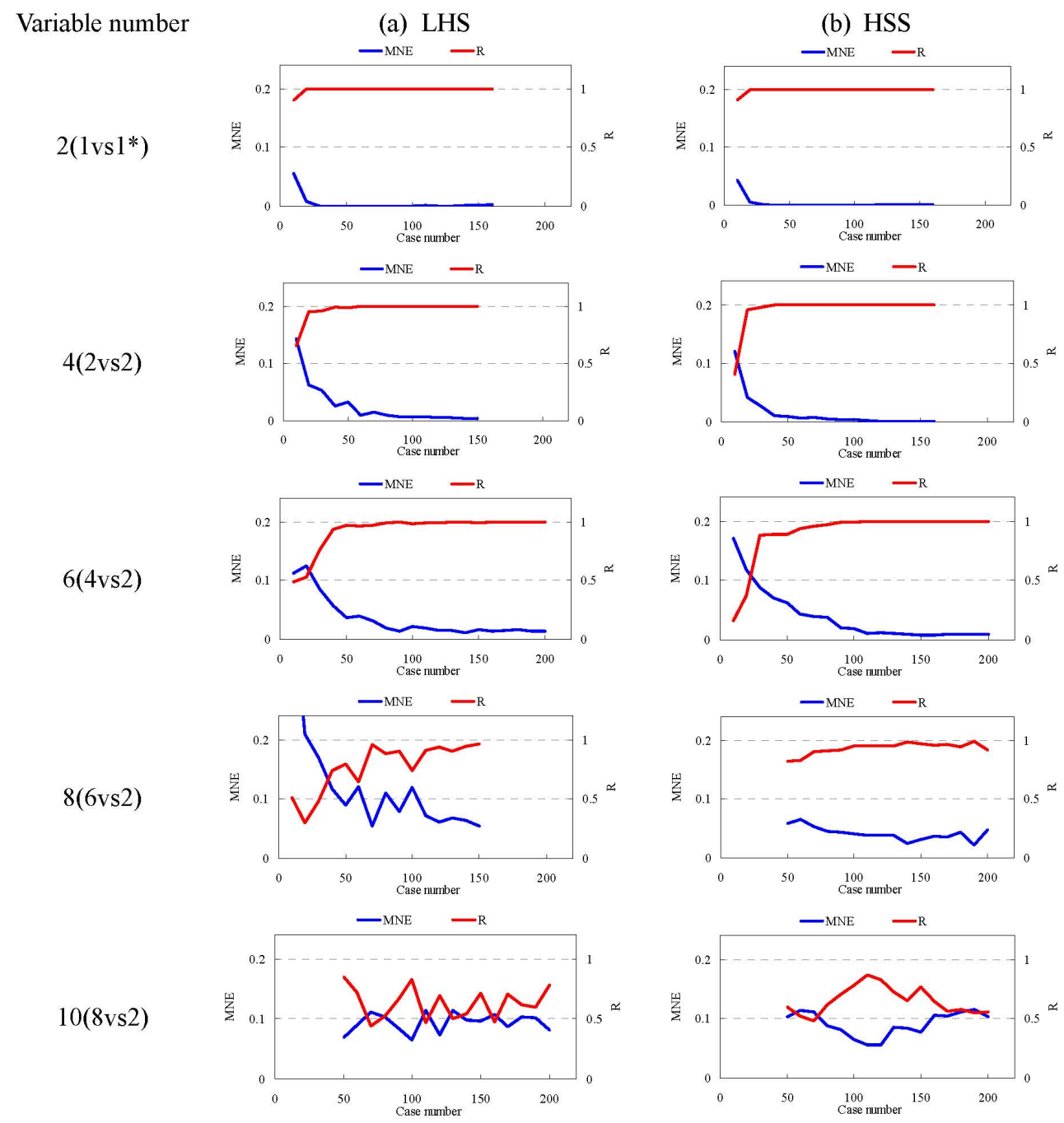

Fig. 7. Sensitivity of prediction performances to sample number and variable numbers through computational experiments $(* 1$ vs. 1 means 1 type of $\mathrm{NO}_{\mathrm{x}}$ emission source and 1 type of VOC emission source).

Shanghai, Guangzhou, as well as Tianjin (to the south of Beijing) and Hong Kong, due to the high density of $\mathrm{NO}_{\mathrm{x}}$ from local emission sources. This is consistent with the observational studies, which also indicated that the urban centers are located in "VOC-limited" region. Chou et al. (2009) suggested that Beijing urban area was located in "VOC-limited" region according to the observation of $\mathrm{NO}, \mathrm{NO}_{\mathrm{x}}$ and $\mathrm{NO}_{\mathrm{y}}$ at the Peking University site during 15 August to 11 September in 2006. Tang et al. (2008) suggested that Xujiahui, the city center of Shanghai, was located in "VOC-limited" region based on the observational $\mathrm{VOCs} / \mathrm{NO}_{\mathrm{x}}$ ratio during high ozone days in 2006. Shao et al. (2009) and Zhang et al. (2008) suggested that the surface ozone in Guangzhou urban area was generally in "VOC-limited regime" through an observation-based model for July 2000 and October 2004, respectively. Some observed studies also indicated that the downwind rural area was located in "NOx-limited" region
(T. Wang et al., 2006; Y. Wang et al., 2009), that is consistent with our results.

The spatial distributions of $\mathrm{NO}_{\mathrm{y}}$ mixing ratio and the peak ratio are roughly consistent in all 3 cities. That suggests that the peak ratio is as good as $\mathrm{NO}_{\mathrm{y}}$, but the peak ratio further serves an indicator for the degree of $\mathrm{NO}_{\mathrm{x}}$ emissions reduction necessary to go from VOC-limited $\mathrm{NO}_{\mathrm{x}}$-limited - a very important factor when designing an urban ozone control strategy.

High ozone concentrations usually appear in downwind rural areas such as north of Beijing and Guangdong, rather than city centers. The peak ratio changes from 0.8 to 1.2 as the distance from the city center increases. Similarly, the $\mathrm{NO}_{\mathrm{y}}$ mixing ratio changes from $20 \mathrm{ppb}$ to $5 \mathrm{ppb}$ with distance from the city center. These results indicate that $\mathrm{NO}_{\mathrm{x}}$ control is beneficial to ozone reduction in the downwind areas which usually have higher ozone mixing ratios than urban areas. 
(a) $\mathrm{O}_{3}$

Beijing

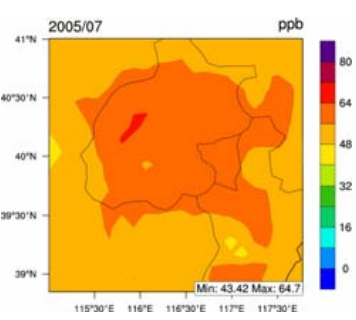

2005/07

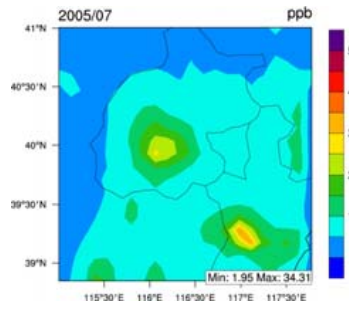

(b) $\mathrm{NO}_{y}$

(c) Peak ratio
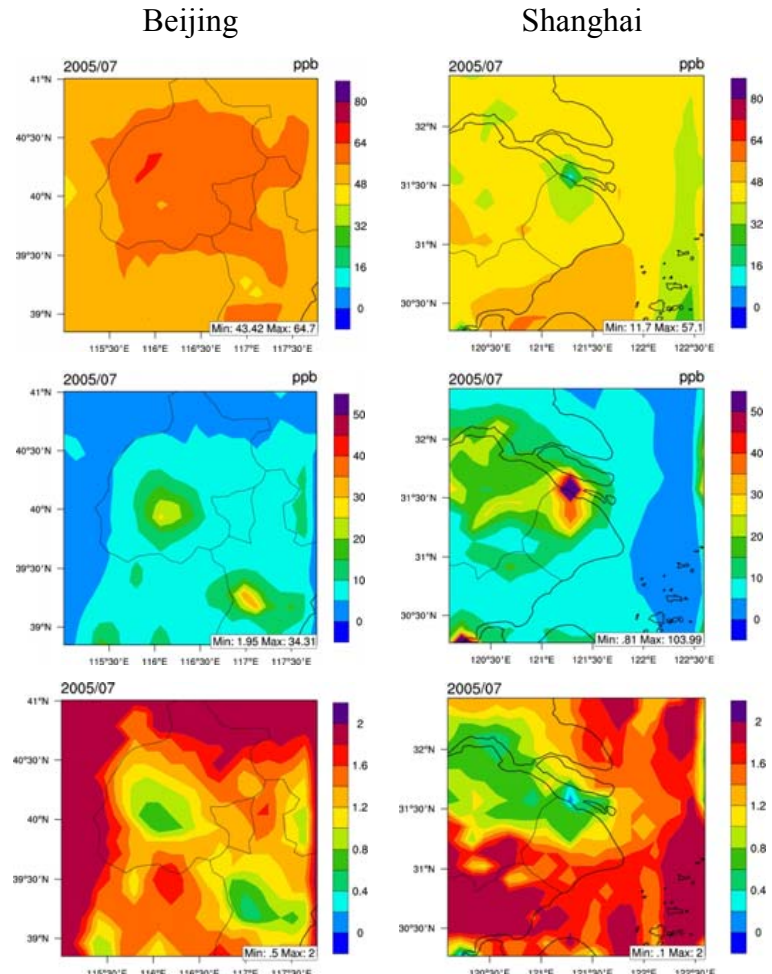
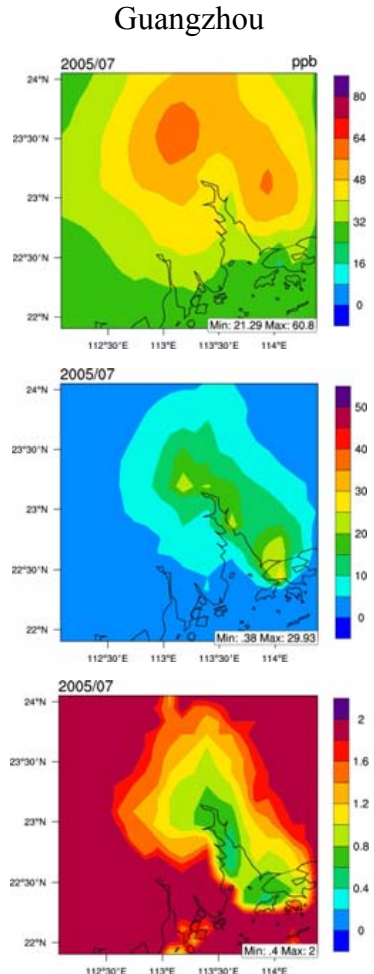

Fig. 8. Ozone chemistry variations in Beijing, Shanghai and Guangzhou (Monthly mean of Ozone, $\mathrm{NO}_{\mathrm{y}}$ mixing ratio, and Peak ratio during afternoon time, 12:00-17:00, July 2005).

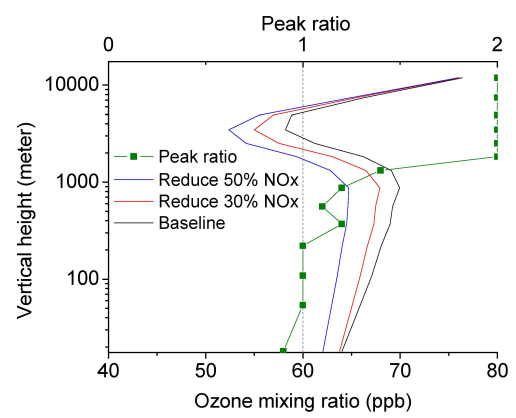

(a) Beijing

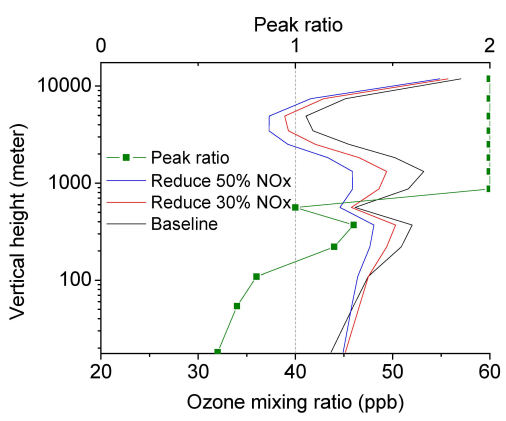

(b) Shanghai

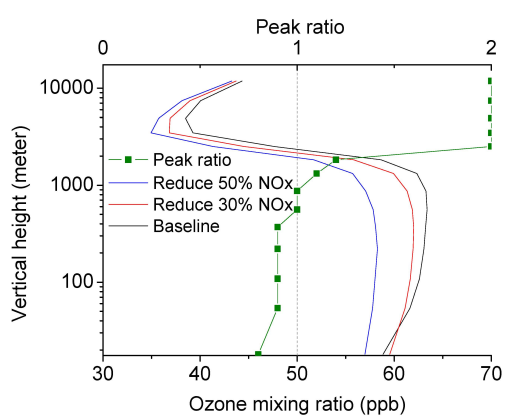

(c) Guangzhou

Fig. 9. Vertical profile of peak ratio and ozone mixing ratio in Beijing, Shanghai and Guangzhou (monthly mean of daily 1-h maxima, July 2005).

The ozone response varies with vertical distance as well. The vertical profiles of the peak ratios and ozone mixing ratios in three cities are shown in Fig. 9. The peak ratio is lower than 1 in the surface layer of three cities. Therefore a $30 \% \mathrm{NO}_{\mathrm{x}}$ reduction barely has an effect on ozone concentrations in the surface layer. While above layer 3-6 (vertical height $72-674 \mathrm{~m}$ ), the peak ratios are higher than 1, indicating $\mathrm{NO}_{\mathrm{x}}$ reductions will reduce ozone concentrations. When $\mathrm{NO}_{\mathrm{x}}$ emissions are reduced 30-50\%, ozone concentrations change. Although the $\mathrm{NO}_{\mathrm{x}}$ emission reductions may not re- duce local urban ozone levels, they can reduce the downwind transport of ozone and precursors and thus the regional air quality benefit can be significant.

Due to the variation of in-situ meteorological conditions, including temperature, humidity, sunlight radiation density, as well as wind speed and precipitation, the ozone chemistry varies significantly temporally. Large differences are found in the comparison of averaged ozone isopleths for higher ozone days $(>70 \mathrm{ppb})$ and lower ozone days $(<30 \mathrm{ppb})$ in the three cities (see in Fig. 10). During days with higher 

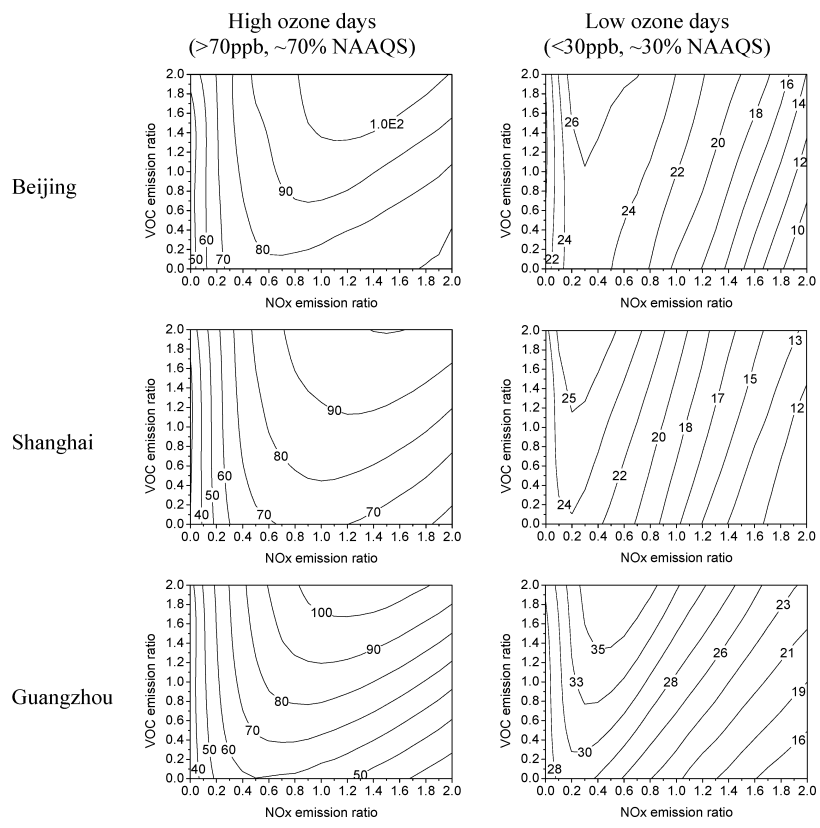

Fig. 10. Averaged ozone isopleths for high and lower ozone days in three cities.

ozone ( $>70 \mathrm{ppb}$ ) under favorable meteorological conditions for photochemical production of ozone, the ozone response is mostly $\mathrm{NO}_{\mathrm{x}}$-limited, with a peak ratio larger than 0.8 . Reductions of $\mathrm{NO}_{\mathrm{x}}$ emissions will reduce ozone concentrations. However, days with lower ozone $(<30 \mathrm{ppb})$, the effects of $\mathrm{NO}_{\mathrm{x}}$ emission reductions are negative for ozone, a peak ratio lower than 0.5 , mainly due to NO titration of ozone under high $\mathrm{NO}_{\mathrm{x}}$ emissions $\left(\mathrm{NO}_{\mathrm{x}}\right.$-rich conditions). This indicates that control of $\mathrm{NO}_{\mathrm{x}}$ emissions will reduce ozone concentrations during periods with high photochemical pollution. This conclusion is consistent with an observational study during an extremely high ozone period of June-July 2005 in Beijing (T. Wang et al., 2006). They found a positive $\mathrm{O}_{3}-\mathrm{NO}_{\mathrm{y}}$ correlation over entire observed $\mathrm{NO}_{\mathrm{y}}$ concentration range which suggested an important role of $\mathrm{NO}_{\mathrm{x}}$ in the formation of $\mathrm{O}_{3}$ in Beijing.

\subsubsection{Evaluation of impacts from individual source categories}

Sensitivity analyses were conducted using the ozone RSM case HSS6-200 to understand the non-linear impacts of different source changes on surface ozone concentrations. Following other sensitive studies (Yarwood et al., 2005; Koo et al., 2009), we defined the "ozone response" as the change ratio of ozone to the change ratio of emission $\left(\frac{\Delta \text { Conc_O}_{3}}{\text { Conc_O}_{3}} /(1\right.$-Emission_ratio $\left.)\right)$, to evaluate the control effects of each source category. From RSM results, the "ozone response" can be calculated across a large range of emissions (from $10 \%$ control to $100 \%$ control), as seen in Fig. 11 .
First, we compared the impact of each source category under the baseline emissions of other source categories, i.e., to calculate the difference between a scenario in which one source category changes emissions and another in which no source category changes. As shown in Fig. 11a, ozone responses to the changes of anthropogenic NMVOC (up to $100 \%$ control) are positive, with a $15-18 \%$ ozone reduction in Beijing and Shanghai, and 25-30\% ozone reduction in Guangzhou. The benefit for ozone reduction from both local and regional VOC emission control is always recognizable. Therefore, VOC control can be an effective choice to reduce ozone if $\mathrm{NO}_{\mathrm{x}}$ emissions stay at the same level.

Although the total $\mathrm{NO}_{\mathrm{x}}$ emission reductions usually reduce ozone concentrations when ozone levels are high, as discussed in the previous section, the ozone response to $\mathrm{NO}_{\mathrm{x}}$ emission changes of different source categories are different. Regional $\mathrm{NO}_{\mathrm{x}}$ sources are strong contributors to ozone concentration (10-20\% ozone sensitivity in each city), while local $\mathrm{NO}_{\mathrm{x}}$ emission source categories are negative contributors until more stringent emission reduction levels are reached (respectively $60 \%, 90 \%$ and $80 \%$ control in Beijing, Shanghai and Guangzhou by recalculation of the combined control effects of two local $\mathrm{NO}_{\mathrm{x}}$ emission source categories). The reason is that the control of regional $\mathrm{NO}_{\mathrm{x}}$ emissions could significantly reduce imported ozone (West et al., 2009), but the control of local $\mathrm{NO}_{\mathrm{x}}$ emissions has negative effects under a VOC-limited regime. These results suggest that local controls are insufficient to solve a regional air quality problem. For example, local $\mathrm{NO}_{\mathrm{x}}$ emission reductions will increase the local ozone mixing ratio. Synchronous control of VOCs and regional emissions must be taken into account.

The non-linear relationship of ozone response to precursor emissions is obvious. With the greater emission reductions, ozone concentration is more sensitive to precursor emissions which are shown by the grey line in Fig. 11a. These results suggest that the effectiveness of $\mathrm{NO}_{\mathrm{x}}$ emission reductions is strengthened with stricter control efforts. In addition, the interactions among different source categories are obvious. The red lines in Fig. 11a (synchronous control of all emission source categories) are above the grey lines (sum of separate controls on each source category) when over $30 \%$ of emissions are reduced.

In order to explore the nonlinear effects among different source categories, we also compared the impact of each source category under the synchronous control of other source categories. Synchronous control means that all emission source categories are controlled by the same Emission Ratio. The impact of each source category under the synchronous control of other source categories is evaluated through the difference between a synchronous control scenario of all source categories and a scenario in which the specific source category does not change.

As seen in Fig. 11b, the benefit of decreasing VOC emissions declines with greater levels of $\mathrm{NO}_{\mathrm{x}}$ emission reductions, and ozone concentrations are more sensitive to $\mathrm{NO}_{\mathrm{x}}$ 


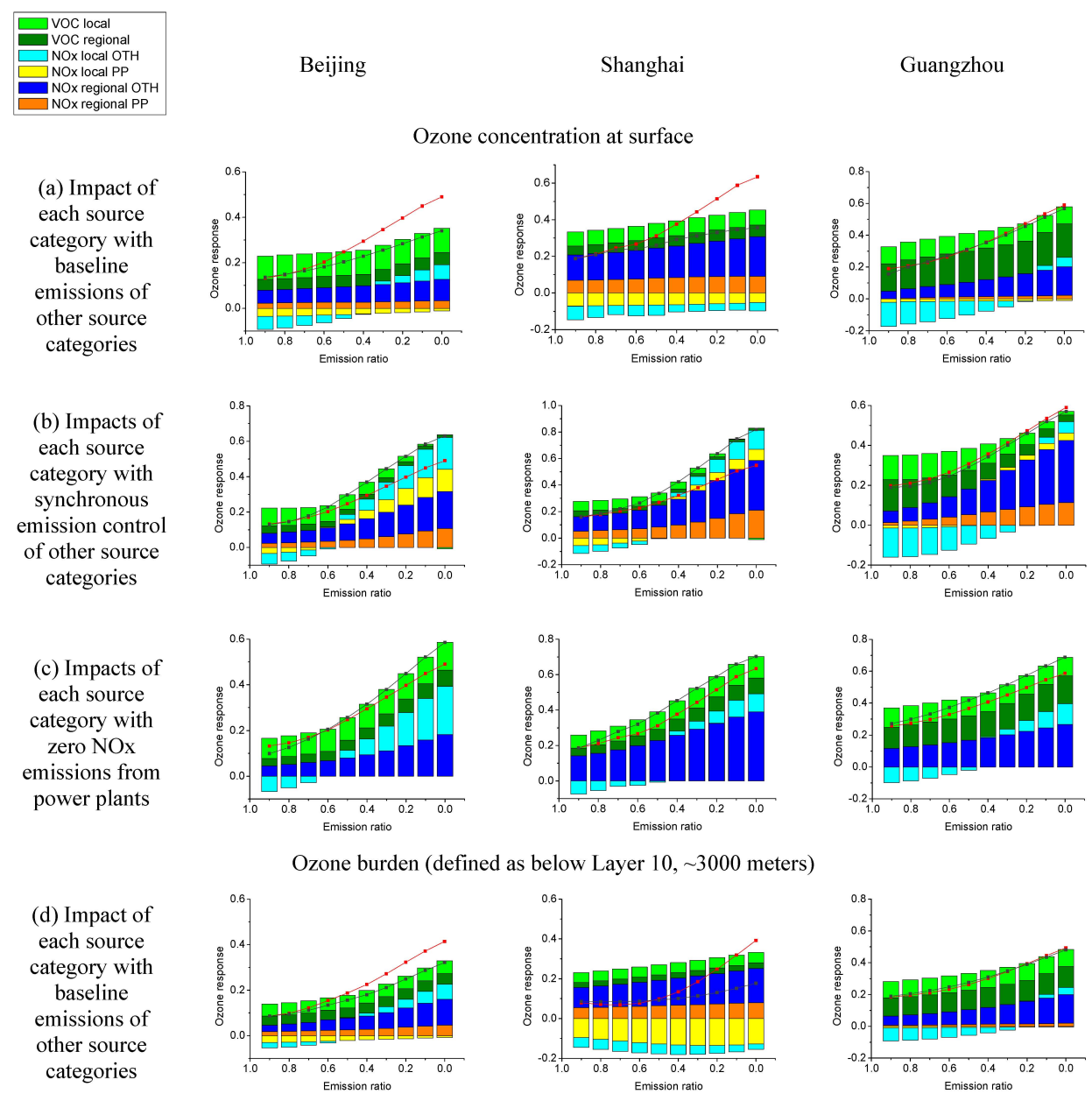

Fig. 11. Ozone response to the stepped control of individual source category in 3 cites. (Ozone response $=$ Change ratio of Ozone/Change ratio of Emission; red solid lines indicate synchronous control of all source categories; colored columns are ozone response to the changes of each emission source category; grey solid lines indicate sum of separate control on each emission source category; all values are averaged of 1-h maxima ozone in high ozone days in July, 2005).

emission reductions at higher control levels, compared to VOC emission reductions. This is partly due to the fact that biogenic VOC emissions are not controlled, changing ozone chemistry to a $\mathrm{NO}_{\mathrm{x}}$-limited regime at high levels of $\mathrm{NO}_{\mathrm{x}}$ emission reductions. Compared to Fig. 11a, the ozone response to regional $\mathrm{NO}_{\mathrm{x}}$ emissions increases and the response to local $\mathrm{NO}_{\mathrm{x}}$ emissions changes to positive at high levels of $\mathrm{NO}_{\mathrm{x}}$ emission reductions (see Fig. 11b). This should be considered when assessing the impacts of initial emission control actions, especially for $\mathrm{NO}_{\mathrm{x}}$ emission control. For example, when the $\mathrm{NO}_{\mathrm{x}}$ emissions from power plants were set to zero in RSM, the ozone response to other $\mathrm{NO}_{\mathrm{x}}$ emission categories was considerably enhanced, seen in Fig. 11c relative to Fig. 11a. The impact of reducing $\mathrm{NO}_{\mathrm{x}}$ emissions from the other source categories was enhanced 1-2 times. To avoid the negative impact on ozone concentrations, the minimum reductions of local $\mathrm{NO}_{\mathrm{x}}$ emissions are from $60 \%$ to $40 \%$ in Beijing, from $100 \%$ to $50 \%$ in Shanghai, from
$80 \%$ to $60 \%$ in Guangzhou. Therefore, $\mathrm{NO}_{\mathrm{x}}$ emission control should be significantly enhanced to reduce ozone concentrations in China.

Responses of ozone burdens to precursor emissions over the PBL (defined as layer 1-10, up to $3000 \mathrm{~m}$ ) are shown in Fig. 11d. Compared to the responses of surface concentration (as shown in Fig. 11a), sensitivities of ozone burdens to VOC are smaller in all cities, mainly because of changes in ozone chemistry in the vertical profile. The negative impacts from $\mathrm{NO}_{\mathrm{x}}$ emission reductions at local area sources become weaker. However, the negative impacts from $\mathrm{NO}_{\mathrm{x}}$ emission reductions at power plants are enlarged in Shanghai, due to the changes of ozone responses at different vertical height, as shown in Fig. 12. Sensitivity of ozone to $\mathrm{NO}_{\mathrm{x}}$ emissions from area sources decreases in the upper layers, but the sensitivity of ozone to power plant $\mathrm{NO}_{\mathrm{x}}$ emissions increases over the PBL. Sensitivity of ozone to VOC emission decreases from Layer 1 to 12. The dominant sources in the upper layers 


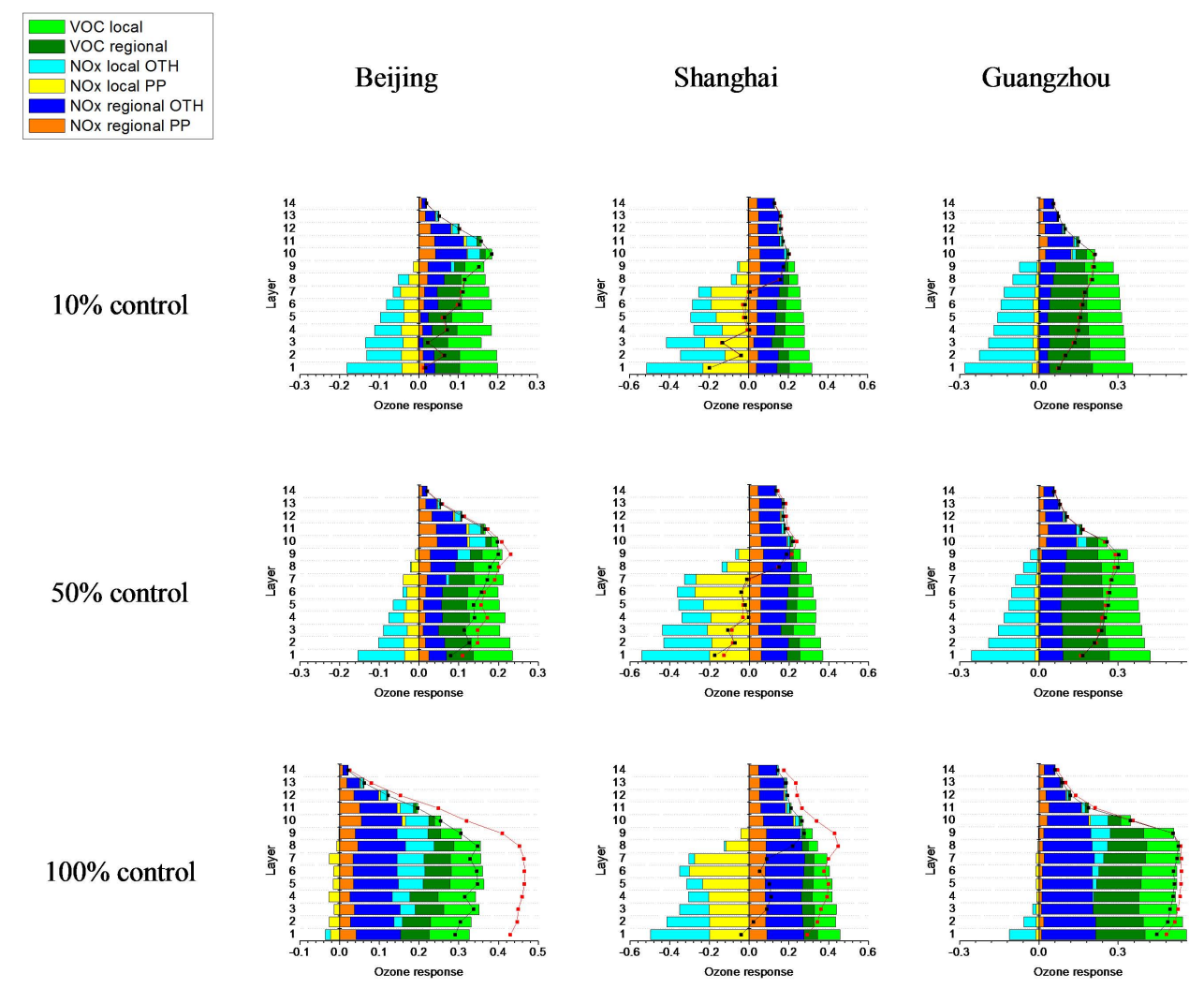

Fig. 12. Vertical profile Ozone response to the stepped control of individual source category in 3 cites. (Ozone response $=$ Change ratio of Ozone/Change ratio of Emission; red solid lines indicate synchronous control on all source categories; colored columns are ozone response to the changes of each source category; grey solid lines indicate sum of separate control on each source category; the heights of layers 1-14 above ground are 36, 72, 145, 294, 444, 674, 1070, 1568, 2093, 2940, 3991, 5807, 9057, $14648 \mathrm{~m}$ respectively; all values are averaged of ozone during afternoon time, 12:00-17:00 in July, 2005).

(above Layer 10) are regional $\mathrm{NO}_{\mathrm{x}}$ emissions. The transitions of local $\mathrm{NO}_{\mathrm{x}}$ impacts from low layers to upper layers are noticeable in the three cities, and the negative impacts in lower layers are weakened and positive impacts in the upper layers (which contribute to regional air quality) are enhanced when strengthening $\mathrm{NO}_{\mathrm{x}}$ emission control efforts.

\subsubsection{Suggestions regarding control policies to achieve the air quality standards}

During the simulation period (July 2005), high ozone episodes that violated the National Ambient Air Quality Standards for ozone occurred in the three cities, as seen in Fig. 13a. The downwind rural areas usually had higher $\mathrm{O}_{3}$ mixing ratios than the urban areas, as shown in Fig. 8. Analysis of the Beijing surface observed $\mathrm{O}_{3}$ mixing ratios in seven monitoring sites also indicated $\mathrm{O}_{3}$ mixing ratios in Dingling (a downwind rural site in Beijing) were on average 10\% (up to $60 \%$ ) higher than the other urban sites during the high ozone period. To guarantee attainment in both urban and rural areas, we chose a policy target of $80 \%$ of the National Ambient Air Quality Standard of China, Class II (i.e., the
Class I standard of a 1-h maximum below $160 \mu \mathrm{g} \mathrm{m}^{-3}$, or approximately $80 \mathrm{ppb}$ ).

RSM allows us to calculate the emission reduction ratio necessary to attain a target concentration (i.e., $80 \mathrm{ppb}, 1$-h maximum). In order to attain this target, several optional control scenarios with various control ranges were designed according to the RSM results (HSS6-200 case). The reductions required are different when controlling the various source categories, as shown in Table 4.

Controlling local $\mathrm{NO}_{\mathrm{x}}$ emissions only requires reduction of $90 \%, 95 \%$ and $85 \%$ for Beijing, Shanghai and Guangzhou, respectively, as seen in option 1. Controlling local VOC emissions only is insufficient to attain the target. Controlling both local $\mathrm{NO}_{\mathrm{x}}$ and VOC emissions only reduced the necessary local $\mathrm{NO}_{\mathrm{x}}$ emission reductions in Beijing from $90 \%$ in option 1 to $80 \%$ in synchronous control, and no changes in Shanghai and Guangzhou. As discussed earlier, this is because the impact of VOC emission reductions is small under higher $\mathrm{NO}_{\mathrm{x}}$ reduction levels. In addition, the regional contribution is more significant than local impacts. If we control both local and regional $\mathrm{NO}_{\mathrm{x}}$ emissions, 
Table 4. Optional $\mathrm{NO}_{\mathrm{x}} / \mathrm{VOC}$ emission reduction ratios to meet the National Ambient Air Quality Standard in China for ozone, Class I (1-h maximal concentration, $160 \mu \mathrm{g} \mathrm{m}^{-3}$ ).

\begin{tabular}{|c|c|c|c|c|c|c|}
\hline & Local $\mathrm{NO}_{\mathrm{x}} \mathrm{PP}$ & Local $\mathrm{NO}_{\mathrm{x}}$ Other & Local VOC & Regional $\mathrm{NO}_{\mathrm{X}} \mathrm{PP}$ & Regional $\mathrm{NO}_{\mathrm{x}}$ Other & Regional VOC \\
\hline \multicolumn{7}{|l|}{ Beijing } \\
\hline Option 1 & $90 \%$ & $90 \%$ & & & & \\
\hline Option 2 & $80 \%$ & $80 \%$ & $80 \%$ & & & \\
\hline Option 3 & $80 \%$ & $80 \%$ & & $80 \%$ & & \\
\hline Option 4 & $75 \%$ & $75 \%$ & & $75 \%$ & $75 \%$ & \\
\hline Option 5 & $65 \%$ & $65 \%$ & $65 \%$ & $65 \%$ & $65 \%$ & $65 \%$ \\
\hline Option 6 & $80 \%$ & $60 \%$ & $60 \%$ & $80 \%$ & $60 \%$ & $60 \%$ \\
\hline \multicolumn{7}{|l|}{ Shanghai } \\
\hline Option 1 & $95 \%$ & $95 \%$ & & & & \\
\hline Option 2 & $95 \%$ & $95 \%$ & $95 \%$ & & & \\
\hline Option 3 & $85 \%$ & $85 \%$ & & $85 \%$ & & \\
\hline Option 4 & $80 \%$ & $80 \%$ & & $80 \%$ & $80 \%$ & \\
\hline Option 5 & $75 \%$ & $75 \%$ & $75 \%$ & $75 \%$ & $75 \%$ & $75 \%$ \\
\hline Option 6 & $80 \%$ & $65 \%$ & $65 \%$ & $80 \%$ & $65 \%$ & $65 \%$ \\
\hline \multicolumn{7}{|c|}{ Guangzhou } \\
\hline Option 1 & $85 \%$ & $85 \%$ & & & & \\
\hline Option 2 & $85 \%$ & $85 \%$ & $85 \%$ & & & \\
\hline Option 3 & $80 \%$ & $80 \%$ & & $80 \%$ & & \\
\hline Option 4 & $75 \%$ & $75 \%$ & & $75 \%$ & $75 \%$ & \\
\hline Option 5 & $70 \%$ & $70 \%$ & $70 \%$ & $70 \%$ & $70 \%$ & $70 \%$ \\
\hline Option 6 & $80 \%$ & $60 \%$ & $60 \%$ & $80 \%$ & $60 \%$ & $60 \%$ \\
\hline
\end{tabular}

Note: Option 1 - local $\mathrm{NO}_{\mathrm{x}}$ control only; Option 2 - local source categories control only; Option 3 - power plant and local $\mathrm{NO}_{\mathrm{x}}$ control only; Option 4 - $\mathrm{NO}_{\mathrm{x}}$ control only; Option 5 - control of all source categories; Option 6 - maximum control of power plant.

the synchronous control of regional power plant $\mathrm{NO}_{\mathrm{x}}$ emissions in option 3 will reduce the necessary local $\mathrm{NO}_{\mathrm{x}}$ emission reductions from $90 \%, 95 \%$, and $85 \%$ to $80 \%, 85 \%$ and $80 \%$ in Beijing, Shanghai and Guangzhou, respectively. The synchronous reductions of all regional $\mathrm{NO}_{\mathrm{x}}$ emissions will reduce the necessary local $\mathrm{NO}_{\mathrm{x}}$ reductions to $75 \%, 80 \%$ and $75 \%$ in option 4. Additional synchronous controls on both local and regional VOC emissions are considered in option 5 and 6 . The requirements of all emission reductions are $65 \%, 75 \%$ and $70 \%$ respectively for Beijing, Shanghai and Guangzhou in option 5. Since power plant are relatively easier to control, in option 6 we assumed $\mathrm{NO}_{\mathrm{x}}$ emissions from power plants were reduced $80 \%$ and emissions from other source categories were reduced $60 \%$ and $65 \%$ and $60 \%$ for Beijing, Shanghai and Guangzhou respectively.

Ozone responses under the control strategies are given in Fig. 13a. Clear improvements resulting from emission reductions are shown during high ozone concentrations, with ozone mixing ratios reduced to $<80 \mathrm{ppb}$. However, negative impacts exist during lower ozone concentrations, especially for options 1, 3 and 4 which only assume $\mathrm{NO}_{\mathrm{x}}$ emission reductions. In order to avoid the risk of ozone enhancement by $\mathrm{NO}_{\mathrm{x}}$ reductions under a VOC-limited regime, VOC emissions should be synchronously controlled, as in options 5 and
6. The effect of the reductions is noticeable over the entire region. The comparison of monthly averaged 1-h maximum ozone concentrations between before-controlled (Fig. 13b) and after-controlled option 6 (Fig. 13c) indicates that the regional air quality surrounding the three cities improves significantly.

RSM can be applied to design the optimal (e.g., least-cost) control targets (Wang and Milford et al., 2001; Fu et al., 2006). When available $\mathrm{NO}_{\mathrm{x}} / \mathrm{VOC}$ control technologies are applied, the cumulative control cost functions can be estimated for each emission source categories. The quantitative relationship between ozone concentration and emission control cost can be determined through RSM. With a certain environmental target (e.g., attainment of national ambient air quality standard), the cost-optimized control ratio for each emission source category can be calculated.

\section{Conclusions}

An RSM for ozone control analysis was successfully developed using the CMAQ air quality model. Through computational experiments, key parameters of ozone RSM development were tested and determined. The performance is better 
(a) Daily variation in city center (Sorting days by ozone from high to low, daily 1-h maxima)
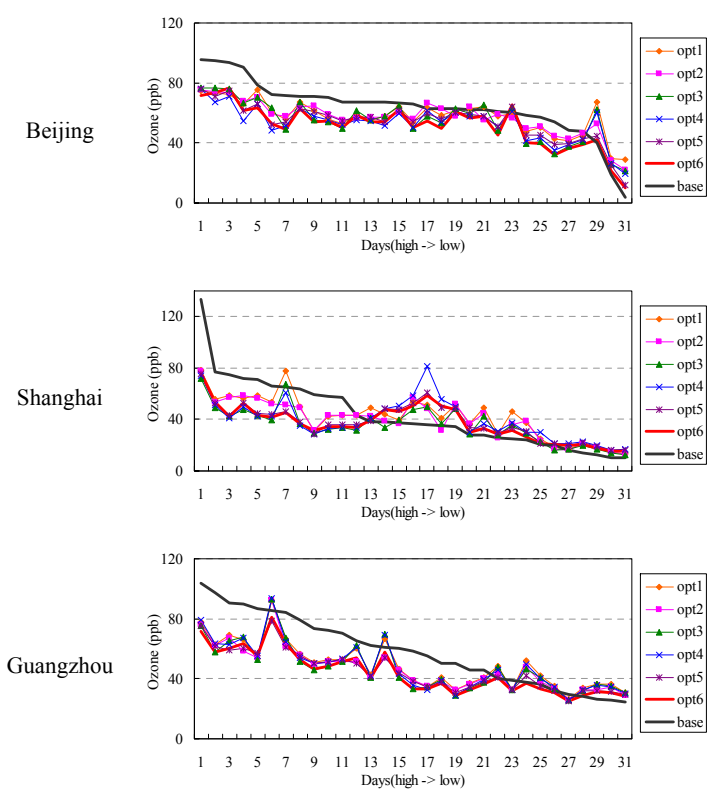

(b) Base
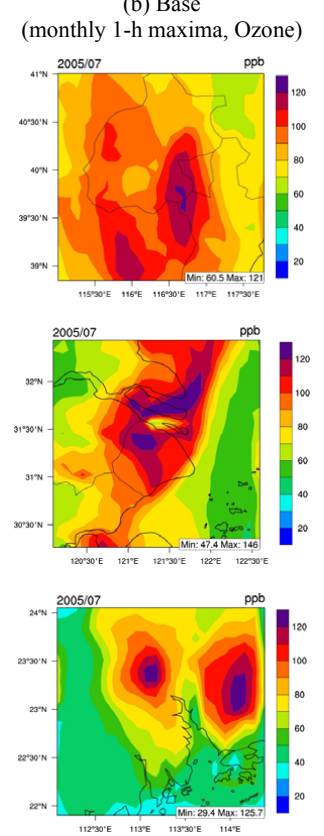

(c) Opt 6-control (monthly 1 -h maxima, Ozone)
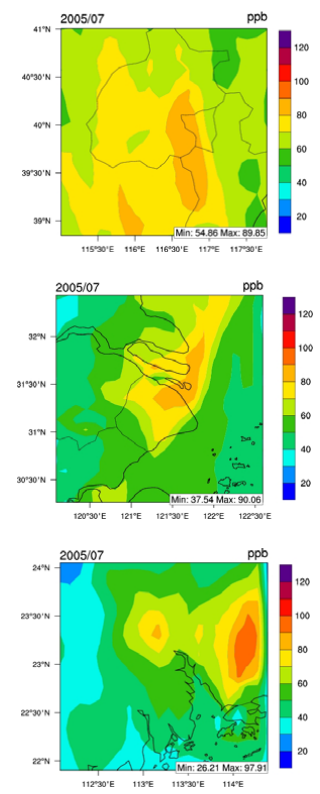

Fig. 13. Effectiveness of $\mathrm{NO}_{\mathrm{x}} / \mathrm{VOC}$ control strategies to achieve secondary national ozone standards in 3 cities.

if the maximum number of variables involved in statistical interpolation does not exceed eight. Margin processing in sampling is recommended to improve the prediction performance, reducing MNEs by half. However, the optimal number varies by RSM designs.

The peak ratio appears to be a useful index to understand ozone formation in response to control of $\mathrm{NO}_{\mathrm{x}}$ and $\mathrm{VOC}$ emissions. Spatial and temporal variations must be considered when evaluating the effects of emission control efforts. In terms of horizontal distribution, $\mathrm{NO}_{\mathrm{x}}$ control is usually beneficial for the downwind areas which usually have a higher ozone concentration than urban centers. The control of $\mathrm{NO}_{\mathrm{x}}$ emissions provides considerable benefits in the upper layers which can reduce the downwind transport of ozone. The control of $\mathrm{NO}_{\mathrm{x}}$ emissions is likely to be more effective than VOC emissions control during heavily polluted episodes.

Different emission source categories affect ozone through different mechanisms. Ozone responses to VOC emission changes are always positive under the baseline emissions of other source categories. However, the effects of VOC emissions reductions significantly decrease with strengthening $\mathrm{NO}_{\mathrm{x}}$ emission control. Therefore, the control of $\mathrm{NO}_{\mathrm{x}}$ emissions must be considered jointly with VOC control to reduce urban local ozone. Regional $\mathrm{NO}_{\mathrm{x}}$ source categories are important contributors to ozone concentration (10-20\% ozone sensitivity in Beijing, Shanghai and Guangzhou), while local $\mathrm{NO}_{\mathrm{x}}$ emission source categories are negative contributors at the surface because of the NO titration of ozone under $\mathrm{NO}_{\mathrm{x}}$ rich urban areas. Local controls cannot alone resolve the re- gional ozone issue, and thus synchronous control of VOC and $\mathrm{NO}_{\mathrm{x}}$ emissions must be taken into consideration.

A comprehensive control policy focused on multiple source categories at both the local and regional levels is necessary to mitigate the ozone problem in China. Several control strategies are designed to meet this national ozone standard. The effectiveness of $\mathrm{NO}_{\mathrm{x}}$ and VOC controls are obvious during high ozone periods ( $>80 \mathrm{ppb}$ ), and ozone levels can be reduced to $80 \mathrm{ppb}$. One of the effective strategies is to reduce $80 \%$ of $\mathrm{NO}_{\mathrm{x}}$ emissions from power plants and reduce about $60 \% \mathrm{NO}_{\mathrm{x}}$ emissions from other source categories and $60 \%$ VOC emissions in Beijing, Shanghai and Guangzhou.

Our findings here are limited to the modeling cases in this study due to the atypical meteorological conditions as well as the uncertainties from simulations and predictions. The ozone sensitivities may still suffer from uncertainties in the emission inventory. Therefore, it is important for future work to better understand the precursor emission inventory, especially for VOC emissions. In addition, the potential growth of activities (e.g. energy consumption and vehicle population) is a substantial challenge for air quality which requires both a more sustainable energy policy and a better-planned control strategy in the future.

Acknowledgements. The study was financially supported by the National High Technology Research and Development Program of China (2006AA06A309), Natural Science Foundation of China (20921140409), and U.S. EPA. The authors thank to Thomas J. Santner and Gang Han at Ohio State University for their help on MperK program; Jeremy Schreifels and Chuck Cnfreed from U.S. EPA for their great help in editing. 
Edited by: J. G. Murphy

\section{References}

Amann, M., Bertok, I., Borken, J., Chambers, A., Cofala, J., Dentener, F., Heyes, C., Hoglund, L., Klimont, Z., Purohit, P., Rafaj, P., Schöpp, W., Toth, G., Wagner, F., and Winiwarter, W.: A tool to combat air pollution and climate change simultaneously. Methodology report, International Institute for Applied Systems Analysis (IIASA), Laxenburg, Austria, 2008.

Box, G. E. P. and Draper N.: Response Surfaces, Mixtures, and Ridge Analyses, Second Edition of [Empirical Model-Building and Response Surfaces, 1987], Wiley, 2007.

Byun, D. W. and Schere, L. K.: Review of the governing equations,computational algorithms and other components of the models-3 Community Multiscale Air Quality(CMAQ) Modeling System, Appl. Mech. Rev., 59(2), 51-77, 2006.

Chou, C. C.-K., Tsai, C.-Y., Shiu, C.-J., Liu, S. C., and Zhu, T.: Measurement of $\mathrm{NO}_{\mathrm{y}}$ during Campaign of Air Quality Research in Beijing 2006 (CAREBeijing-2006): Implications for the ozone production efficiency of $\mathrm{NO}_{\mathrm{x}}$, J. Geophys. Res., 114, D00G01, doi:10.1029/2008JD010446, 2009.

Cohan, D. S., Hakami, A., Hu, Y. T., and Russell, A. G.: Nonlinear response of ozone to emissions: source apportionment and sensitivity analysis, Environ. Sci. Technol., 39, 6739-6748, 2005.

Cohan, D. S., Boylan, J. W., Marmur, A., and Khan, M. N.: An integrated framework for multipollutant air quality management and its application in Georgia, Environ. Manage., 40, 545-554, 2007.

Duan, J.-C., Tan, J.-H., Yang, L., Wu, S., and Hao, J.-M.: Concentration, sources and ozone formation potential of volatile organic compounds (VOCs) during ozone episode in Beijing, Atmos. Res., 88, 25-35, 2008.

Dunker, A. M., Yarwood, G., Ortmann, J. P., and Wilson, G. M.: Comparison of source apportionment and source sensitivity of ozone in a three-dimensional air quality model, Environ. Sci. Technol., 36, 2953-2964, 2002.

ENVIRON: User's guide to the Comprehensive Air Quality Model with Extensions (CAMx). ENVIRON International Corporation, Novato, CA, 2002.

Fu, J. S., Brill Jr, E. D., and Ranjithan, S. R.: Conjunctive use of models to design cost-effective ozone control strategies, J. Air Waste Manage. Assoc., 56, 800-809, 2006.

Hakami, A., Odman, M. T., and Russell, A. G.: High-order, direct sensitivity analysis of multidimensional air quality models, Environ. Sci. Technol., 37, 2442-2452, 2003.

Hammersley, J.: Monte Carlo methods for solving multivariable problems, Proceedings of the New York Academy of Science, 86, 844-874, 1960.

Iman, R. L., Davenport, J. M.. and Zeigler, D. K.: Latin Hypercube Sampling (Program User's Guide). Technical Report SAND791473, Sandia National Laboratories, Albuquerque, NM, 1980.

Jang, J. C., Jeffries, H. E., and Tonnesen, S.: Sensitivity of ozone to model grid resolution-II. Detailed process analysis for ozone chemistry, Atmos. Environ., 29, 3101-3114, 1995.

Klimont, Z., Cofala, J., Xing, J., Wei, W., Zhang, C., Wang, S., Kejun, J., Bhandari, P., Mathur, R., Purohit, P., Rafaj, P., Chambers, A., and Amann, M.: Projections of $\mathrm{SO}_{2}, \mathrm{NO}_{\mathrm{x}}$ and carbonaceous aerosols emissions in Asia, Tellus B, 61, 602-617, 2009.
Koo, B., Wilson, G. M., Morris, R. E., Dunker, A. M., and Yarwood, G.: Comparison of Source Apportionment and Sensitivity Analysis in a Particulate Matter Air Quality Model, Environ. Sci. Technol., 43, 6669-6675, 2009.

Lei, Y., He, K.-B., Zhang, Q., and Liu, Z.-Y.: Technology-Based Emission Inventory of Particulate Matters (PM) from Cement Industry, Chinese J. Environ. Sci., 29, 2366-2371, 2008.

Li, L., Chen, C.-H., Huang, C., Huang, H.-Y., Li, Z.-P., Fu, S. J., Jang, J. C., and Streets, D. G.: Regional Air Pollution Characteristics Simulation of $\mathrm{O}_{3}$ and $\mathrm{PM}_{10}$ over Yangtze River Delta Region, Chinese Environ. Sci., 29(1), 237-245, 2008.

Liu, X.-H., Zhang, Y., Xing, J., Zhang, Q., Streets, D. G., Jang, C. J., Wang, W.-X., and Hao, J.-M.: Understanding of Regional Air Pollution over China using CMAQ - Part II. Process Analysis and Ozone Sensitivity to Precursor Emissions, Atmos. Environ., 44, 3719-3727, 2010.

Milford, J. B., Russell, A. G., and McRae, G. J.: A New Approach to Photochemical Pollution Control: Implications of Spatial Patterns in Pollutant Responses to Reductions in Nitrogen Oxides and Reactive Organic Gas Emissions, Environ. Sci. Technol., 23, 1290-1301, 1989.

Ohara, T., Akimoto, H., Kurokawa, J., Horii, N., Yamaji, K., Yan, X., and Hayasaka, T.: An Asian emission inventory of anthropogenic emission sources for the period 1980-2020, Atmos. Chem. Phys., 7, 4419-4444, doi:10.5194/acp-7-4419-2007, 2007.

Ran, L., Zhao, C., Geng, F., Tie, X., Tang, X., Peng, L., Zhou, G., Yu, Q., Xu, J., and Guenther, A.: Ozone photochemical production in urban Shanghai, China: Analysis based on ground level observations, J. Geophys. Res., 114, D15301, doi:10.1029/2008JD010752, 2009.

Santner, T. J., Williams, B. J., and Notz, W.: The Design and Analysis of Computer Experiments, Springer Verlag, New York, 2003.

Seinfeld, J. H. and Pandis, S. N.: Atmospheric chemistry and physics: From air pollution to climate change, 241 pp., John Wiley and Sons, Inc., 2006.

Shao, M., Zhang, Y.-H., Zeng, L.-M., Tang, X.-Y., Zhang, J., Zhong, L.-J. and Wang, B.-G.: Ground-level ozone in the Pearl River Delta and the roles of VOC and $\mathrm{NO}_{\mathrm{x}}$ in its production, $\mathrm{J}$. Environ. Manage., 90, 512-518, 2009.

Shih, J. S., Russell, A. G., and McRae, G. J.: An optimization model for photochemical air pollution control, European Journal of Operational Research, 106, 1-14, 1998.

Sillman, S.: The use of $\mathrm{NO}_{\mathrm{y}}, \mathrm{H}_{2} \mathrm{O}_{2}$, and $\mathrm{HNO}_{3}$ as indicators for ozone-NOx-hydrocarbon sensitivity in urban locations. J. Geophys. Res., 100 (D7), 4175-4188. 1995.

Streets, D. G., Bond, T. C., Carmichael, G. R., Fernandes, S. D., Fu, Q., He, D., Klimont, Z., Nelson, S. M., Tsai, N. Y., Wang, M. Q., Woo, J.-H., and Yarber, K. F.: An inventory of gaseous and primary aerosol emissions in Asia in the year 2000, J. Geophys.Res., 108, 8809, doi:10.1029/2002JD003093, 2003.

Streets, D. G., Fu, J. S., Jang, C. J., Hao, J.-M., He, K.-B., Tang, X.-Y., Zhang, Y.-H., Wang, Z.-F., Li, Z.-P., Zhang, Q., Wang, L.T., Wang, B.-Y., and Yu, C.: Air quality during the 2008 Beijing Olympic Games, Atmos. Environ., 41, 480-492, 2007.

Tang, W.-Y., Zhao, C.-S., Geng, F.-H., and Tie, X.: Study of ozone "weekend effect" in Shanghai, Sci. China, 51, 1354-1360, 2008.

Tang, G., Li, X., Wang, Y., Xin, J., and Ren, X.: Surface ozone trend details and interpretations in Beijing, 2001-2006, Atmos. Chem. 
Phys., 9, 8813-8823, doi:10.5194/acp-9-8813-2009, 2009.

Tonnesen, G. S. and Dennis, R. L.: Analysis of radical propagation efficiency to assess ozone sensitivity to hydrocarbons and $\mathrm{NO}_{\mathrm{x}}$ 1. Local indicators of instantaneous odd oxygen production sensitivity, J. Geophys. Res., 105(D7), 9213-9225, 2000.

U.S. Environmental Protection Agency: Technical Support Document for the Proposed Mobile Source Air Toxics Rule: Ozone Modeling, Office of Air Quality Planning and Standards, Research Triangle Park, NC, 2006a.

U.S. Environmental Protection Agency: Technical Support Document for the Proposed PM NAAQS Rule: Response Surface Modeling, Office of Air Quality Planning and Standards, Research Triangle Park, NC, 2006b.

Wang, H., Zhou, L., and Tang, X.: Ozone concentrations in rural regions of the Yangtze Delta in China, J. Atmos. Chem., 54, 255265, 2006.

Wang, L.-H. and Milford, J. B.: Reliability of optimal control strategies for photochemical air pollution, Environ. Sci. Technol., 35, 1173-1180, 2001.

Wang, L.-T., Hao, J.-M., He, K.-B., Wang, S.-X., Li, J.-H., Zhang, Q., Streets, D. G., Fu, J. S., Jang, C. J., Takekawa, H., and Chatani, S.: A Modeling Study of Coarse Particulate Matter Pollution in Beijing: Regional Source Contributions and Control Implications for the 2008 Summer Olympics, J. Air Waste Manage. Assoc., 58, 1057-1069, 2008.

Wang, L.-T., Jang, C., Zhang, Y., Wang, K., Zhang, Q., Streets, D., Fu, J., Lei, Y., Schreifels, J., He, K.-B., Hao, J.-M., Lam, Y. F., Lin, J., Meskhidze, N., Voorchees, S., Evarts, D., and Phillips, S.: Assessment of air quality benefits from national air pollution control policies in China. Part I: Background, emission scenarios and evaluation of meteorological predictions, Atmos. Environ., 44, 3442-3448, 2010.

Wang, S.-X., Zhao, M., Xing, J., Wu, Y., Zhou, Y., Lei, Y., He, K.-B., Fu, L.-X., and Hao, J.-M.: Quantifying the Air Pollutants Emission Reduction during the 2008 Olympic Games in Beijing, Environ. Sci. Technol., 44(7), 2490-2496, doi:10.1021/es9028167, 2010.

Wang, T., Ding, A.-J., Gao, J., and Wu, W.-S.: Strong ozone production in urban plumes from Beijing, China, Geophys. Res. Lett., 33, L21806, doi:10.1029/2006GL027689, 2006.

Wang, X.-S, Li, J.-L., Zhang, Y.-H., Xie, S.-D., and Tang X.-Y.: Ozone source attribution during a severe photochemical smog episode in Beijing, China, Science in China, 39-6, 548-559, 2009.

Wang, Y., Hao, J., McElroy, M. B., Munger, J. W., Ma, H., Chen, D., and Nielsen, C. P.: Ozone air quality during the 2008 Beijing Olympics: effectiveness of emission restrictions, Atmos. Chem. Phys., 9, 5237-5251, doi:10.5194/acp-9-5237-2009, 2009.

Wang, Z., Li, J., Wang, X., Pochanart, P., and Akimoto, H.: Modeling of regional high ozone episode observed at two mountain sites (Mt. Tai and Huang) in East China, J. Atmos. Chem., 55, 253-272, 2006.
Wei, W., Wang, S.-X., Chatani, S., Klimont, Z., Cofala, J., and Hao, J.-M.: Emission and speciation of non-methane volatile organic compounds from anthropogenic sources in China, Atmos. Environ., 42(20), 4976-4988, 2008.

West, J. J., Naik, V., Horowitz, L. W., and Fiore, A. M.: Effect of regional precursor emission controls on long-range ozone transport - Part 1: Short-term changes in ozone air quality, Atmos. Chem. Phys., 9, 6077-6093, doi:10.5194/acp-9-6077-2009, 2009.

Xing, J., Wang, S.-X., Chatani., S., Cofala, J., Klimont, Z., Amann, M., and Hao, J.-M.: Validating Anthropogenic Emissions of China by Satellite and Surface Observations Atmos. Environ., in review, 2010.

Xu, J., Zhang, Y.-H., Fu, J. S., Zheng, S. Q., and Wang, W.: Process analysis of typical summertime ozone episodes over the Beijing area, Sci. Total Environ., 399, 147-157, 2008.

Yarwood, G., Wilson, G., and Morris, R.: Development of the CAMx Particulate Source Apportionment Technology (PSAT), final report, ENVIRON International Corporation, 2005.

Zhang, Y., Vijayaraghavan, K., and Seigneur, C.: Evaluation of Three Probing Techniques in a Three-Dimensional Air Quality Model, J. Geophys. Res., 110, D02305, doi:10.1029/2004JD005248, 2005.

Zhang, Y.-H., Su, H., Zhong, L.-J. , Cheng, Y.-F., Zeng, L.M., Wang, X.-S., Xiang, Y.-R., Wang, J.-L., Gao, D.-F., Shao, M., Fan, S.-J., and Liu, S.-C.: Regional ozone pollution and observation-based approach for analyzing ozone-precursor relationship during the PRIDE-PRD2004 campaign, Atmos. Environ., 42, 6203-6218, 2008.

Zhang, Q., Streets, D. G., Carmichael, G. R., He, K. B., Huo, H., Kannari, A., Klimont, Z., Park, I. S., Reddy, S., Fu, J. S., Chen, D., Duan, L., Lei, Y., Wang, L. T., and Yao, Z. L.: Asian emissions in 2006 for the NASA INTEX-B mission, Atmos. Chem. Phys., 9, 5131-5153, doi:10.5194/acp-9-5131-2009, 2009a.

Zhang, Y., Wen, X.-Y., Wang, K., Vijayaraghavan, K., and Jacobson, M. Z.: Probing into Regional $\mathrm{O}_{3}$ and PM Pollution in the U.S., Part II. An Examination of Formation Mechanisms through a Process Analysis Technique and Sensitivity Study, J. Geophys. Res., 114, D22305, doi:10.1029/2009JD011900, 2009b.

Zhao, Y., Wang, S.-X., Duan, L., Lei, Y., Cao, P.-F., and Hao, J.M.: Primary air pollutant emissions of coal-fired power plants in China: Current status and future prediction, Atmos. Environ., 42, 8442-8452, 2008.

Zhao, Y., Nielsen, C. P., Lei, Y., McElroy, M. B., and Hao, J.: Quantifying the uncertainties of a bottom-up emission inventory of anthropogenic atmospheric pollutants in China, Atmos. Chem. Phys., 11, 2295-2308, doi:10.5194/acp-11-2295-2011, 2011.

Zheng, J., Zhang L.-J., Che, W.-W, Zheng, Z.-Y., and Yin, S.-S.: A highly resolved temporal and spatial air pollutant emission inventory for the Pearl River Delta region, China and its uncertainty assessment, Atmos. Environ., 43, 5112-5122, 2009. 